\title{
PERFORMANCE OF AN EXAMPLE JACK-UP PLATFORM UNDER DIRECTIONAL RANDOM OCEAN WAVES
}

\section{Authors:}

1. Jalal Mirzadehniasar, Centre for Offshore Foundation Systems, The UWA Oceans Institute and ARC CoE for Geotechnical Science and Engineering, University of Western Australia, Australia.

2. Mehrdad Kimiaei, Centre for Offshore Foundation Systems, The UWA Oceans Institute and ARC CoE for Geotechnical Science and Engineering, University of Western Australia, Australia.

3. Mark Jason Cassidy, Centre for Offshore Foundation Systems, The UWA Oceans Institute and ARC $\mathrm{CoE}$ for Geotechnical Science and Engineering, University of Western Australia, Australia.

\section{Keywords:}

1. Wave-spreading

2. Jack-up Platforms

3. Constrained NewWave

4. Random Sea

5. Dynamic Performance

6. Failure Probability

\section{Corresponding Author:}

Full name: Jalal Mirzadehniasar

Telephone: +61- 416826604

Email: jalal.mirzadeh@gmail.com; 20899725@student.uwa.edu.au 


\section{ABSTRACT}

This article presents the results of nonlinear dynamic analyses that explore the effects of directionality and the random nature of ocean waves on the overall structural performance of a sample jack-up platform. A finiteelement model is developed which rigorously includes the effects of the material and geometrical nonlinearities in the structure and the nonlinear soil-structure interaction. Two wave theories, NewWave and Constrained NewWave, are adopted to simulate the water surface and water particle kinematics, which are implemented in the numerical model developed. Analyses are performed for both two and three-dimensional wave models, and the results are compared in terms of the deck and spudcan foundation displacements. The results obtained from the analyses indicate that the inclusion of wave spreading can result in reductions in the deck displacements of the sample jack-up platform. The level of reduction is greater when considerable plasticity occurs in the foundation. Furthermore, the probability of failure can be significantly decreased when the wave-spreading effects are included. In addition, it is shown that the effects of wave-spreading on the response and failure of the sample jack-up is increased when wave period is decreased.

\section{INTRODUCTION}

Jack-up platforms, which are conventionally designed and used as mobile drilling units, have been increasingly used to operate as production platforms in deep waters. Therefore, these self-elevating units are important to the offshore community because of their broad application and unique capacity in field development and operation. The performance of these structures under the action of hostile environmental loading must be evaluated as realistically as possible to enable the owners to safely extend the applicability of jack-up units into new locations and water greater depths. This requirement necessitates progressive enhancement in the current analysis methodologies with respect to the performance assessment of jack-up structures.

Over the past decades, numerical modelling of jack-ups has been substantially developed in three major areas: structural modelling, soil-structure interaction models and ocean wave loading. In the structural-modelling area, geometrical and material nonlinearities and dynamic effects can be effectively modelled [1]. In addition, nonlinear-solutions have been considerably improved, and all of the mentioned capabilities have been incorporated into advanced commercial software (e.g., USFOS). In the geotechnical area, numerous soilspudcan interaction models that include soil nonlinearity have been developed, some of which can straightforwardly be coupled into structural numerical models [2, 3, 4 and 5]. However, despite noticeable 
enhancements in ocean wave mechanics $[6,7,8,9,10$ and 11], the characteristics of real ocean waves are not explicitly represented in the current analysis procedures mainly because modelling all of the factors governing kinematics of ocean waves involve significant numerical complexities and are computationally expensive.

Extreme ocean waves propagate in different directions while carrying a wide range of energies and frequencies. In other words, offshore structures are subjected to random waves that approach simultaneously from different directions. Nevertheless, in the conventional approach recommended by the design guidelines (e.g. API [12]), wave kinematics are deterministically computed by applying regular and unidirectional (2D) wave theories. In these wave models, such as the Stokes 5th order, the effect of the random nature of ocean waves is neglected, and a kinematics reduction factor (e.g. between 0.85 and 1.00 as per API [12]) is generically used to account for the directional spreading effects (3D effects). It should be noted that for drag dominated structures such as jackup platforms, the response is sensitive to the kinematics at the crest, as the horizontal drag forces are maximum at the crest height. However, the kinematic reduction factor, which reflects the reduced kinematics under the highest point of the wave crest [13], cannot represent the effect of wave spreading on a jack-up (or any other spaced offshore structure) as the variation of crest height in the perpendicular direction of the wave is neglected. Given the limitations in the current practice, a more rigorous numerical method is required to accurately and realistically simulate the random nature of extreme ocean waves and their directionality.

There is limited research on the effect of wave spreading and randomness on the dynamic performance of jackup structures under the action of hostile wave environment. Cassidy et al. $[14,15]$ considered the effect of randomness by constraining the deterministic linear NewWave [16] into a completely random background using the Constrained NewWave (CNW) method [17]. However, because the wave was applied on the structure as a 2D water surface elevation, the spreading effect was not studied. On-the-other-hand, Cassidy [18] addressed the effect of wave spreading on the jack-up performance using the directional NewWave; however in this case, the effect of randomness was not explicitly considered. Smith et al. [13] also quantified the level of load reduction in jack-ups using a second-order directional NewWave theory and consequently the effect of randomness again was not explicitly included. This study was extended by Smith et al. [19] and Hoyle et al. [20] by introducing a formula to calculate a kinematic reduction factor based on jack-up dimensions, wave characteristic and water depth and was intended to be applied in conjunction with a regular wave analysis. The formula was proposed by a parametric study conducted using a number of independent variables for five different rig classes. There has also been some advance studies on the directional spreading of ocean waves, such as the research carried out by 
Ewans [21], Forristall and Ewans [22] Gibbs and Taylor [10]. However, the application of these methods to calculate wave loading on and the response of offshore structures remains computationally expensive.

In this study, the effects of fandom backgroundrandomness as well as the-directionality and the random background of ocean waves are explicitly considered for a sample jack-up platform. The main focus is on the modelling of two and three-dimensional waves with the objective to perform a nonlinear dynamic time history analysis for both 2D waves with a kinematics reduction factor and 3D waves and then to compare the results. NewWave and CNW (i.e. NewWaves of the same height and spatial location constrained within $\underline{\text { different random seas) are used to determine the wave actions; thereby, the effects of randommess-the random }}$ background of ocean waves are emphasised. The later method, which accounts for the random background of ocean waves, has not been explicitly used to assess the effect of spreading on the performance of jack-up structures. The scope of this study is to compare the results for the 2D and 3D NewWaves and CNWs on a sample jack-up platform for a limited number of sea-states. This allows for future sensitivity studies to investigate the effects of various structural and environmental input parameters on overall structural response of jack-up platforms under 3D extreme waves.

\section{FRAMEWORK OF JACK-UP MODELLING}

A numerical model is developed using the USFOS software [23] to investigate the effect of wave spreading and random background of waves on the dynamic performance of a jack-up unit. The sample jack-up is assumed to operate at a water depth of $106.7 \mathrm{~m}$. The numerical model of this platform is illustrated in Figure 1. The jack-up structure is symmetrical against three axes (every 1208). The hull structure is supported by three main legs that rest on the seafloor through spudcan foundations. During offshore operation, the hull structure is raised to an elevation of $131.7 \mathrm{~m}$ above the seafloor, as shown in Figure 1. The jack-up legs with a centre-to-centre distance of $46 \mathrm{~m}$ are composed of three vertical members that are stiffened through X-braces and form a triangular truss structure which are modelled by tubular members. The total self-weight of the jack-up platform is $134.2 \mathrm{MN}$. The spudcan diameter is $17 \mathrm{~m}$, the apex angle is 868 , and the amount of preload in each leg is assumed to be 80 MN (i.e., approximately twice the self-weight reaction in each leg). The first three natural periods of the structure are $8.16 \mathrm{~s}$ (sway in the X-direction), $8.15 \mathrm{~s}$ (sway in the Y-direction), and $7.14 \mathrm{~s}$ (rotation about the vertical axis). Different aspects of numerical modelling, including wave loading, structural and geotechnical modelling schemes, are detailed in the following sections. 


\subsection{Wave Modelling}

In the present study, the NewWave and CNW theories are adopted as deterministic and random approaches in wave modelling, respectively. These wave theories are briefly described as follows.

The NewWave theory [16] is a deterministic method that accounts for the spectral composition of the sea-state. By assuming that the surface elevation can be simulated as a Gaussian random process, the expected elevation during an extreme event can be theoretically determined by simulating a large crest elevation, which is particularly useful in offshore engineering. The shape that is statistically most probable and associated with the event's occurrence is applied to model the surface elevation around this extreme event $[4,16]$. For simplicity in the numerical implementation, the NewWave shape is discretised using a finite number $(\mathrm{N})$ of sinusoidal wave components.

To include the effects of wave directionality, this method is extended by introducing another term to represent the wave direction, $\theta$. This 3D NewWave can be discretised using a finite number $(\mathrm{N} \times \mathrm{M})$ of sinusoidal wave components, where $\mathrm{N}$ is the number of frequency components and $\mathrm{M}$ is the number of wave directions.

Because there is a unique relationship between the wave number and the frequency, the spatial dependency can also be included, which leads to the following discrete form of the surface elevation $(\eta)$ for the directional wave [18]:

$\eta(X, Y, \tau)=\frac{\alpha}{\sigma^{2}} \sum_{m=1}^{M} \sum_{n=1}^{N}\left[S_{\eta \eta}\left(\omega_{n}\right) d \omega \cdot D\left(\theta_{m}\right) d \theta\right] \cos \left[k_{n} X \cos \left(\theta_{m}\right)+k_{n} Y \sin \left(\theta_{m}\right)-\omega_{n} \tau\right]$

where $k_{n}$ and $\omega_{n}$ represent the wave number and angular frequency of the $n^{\text {th }}$ frequency component, respectively, $\theta_{\mathrm{m}}$ is the angle of $\mathrm{m}^{\text {th }}$ wave direction, $\alpha$ represents the NewWave crest elevation, $S_{\eta \eta}\left(\omega_{n}\right) d \omega . D\left(\theta_{m}\right) d \theta$ represents the surface elevation spectrum, $\sigma$ is the standard deviation that corresponds to that wave spectrum, $\mathrm{X}=\mathrm{x}-\mathrm{x}_{1}, \mathrm{Y}=\mathrm{y}-\mathrm{y}_{1}$ and $\tau=\mathrm{t}-\mathrm{t}_{1}$ are the distance and time relative to the initial position $\left(\mathrm{x}_{1}\right.$, $\mathrm{y}_{1}$ ) and initial time $\left(\mathrm{t}_{1}\right)$, respectively, and $\mathrm{X}=0, \mathrm{Y}=0$ and $\tau=0$ represent the location and time of the wave crest, respectively. Thus, the spatial field is positioned so that the crest occurs at a user-defined time and position relative to the structure.

$\mathrm{D}(\theta)$ is a directional spreading function, which is a symmetric function around the mean wave direction $\bar{\theta}$ that defines the distribution of wave energy in a sea-state with direction and must satisfy Equation 2.

$\int_{\bar{\theta}-\frac{\pi}{2}}^{\bar{\theta}+\frac{\pi}{2}} D(\theta) d \theta=1$ 
A commonly used directional spreading function in engineering applications is present in Equation 3 , where $\mathrm{n}$ is a positive integer and $\mathrm{C}_{\mathrm{s}}$ is a coefficient such that Equation 2 is satisfied. When $\mathrm{s}$ is zero, the energy is uniformly distributed in all directions. Observations of wind-driven seas show that an appropriate spreading function is a cosine squared function ( $s=2$ ). When a limited fetch restricts the degree of spread, $s=4$ is appropriate [12].

$D(\theta)=C_{s} \cdot \cos ^{s}(\theta-\bar{\theta})$

Taylor et al. [17] and Cassidy et al. [14] showed that the 2D CNWs, which are generated mathematically by constraining a NewWave (of a predetermined crest height) in a random time series that defines the background surface elevation, can be used as an alternative for 3-hr randomly generated waves. This process is rigorously performed, where the constrained sequence is statistically indistinguishable from the original random sequence. This approach provides the required extreme response that on average correlates with the occurrence of a large wave in a random sea-state [17]. This method can be extended to generate directional CNWs.

Wavelets of different wave lengths, amplitudes and periods that travel at varying speeds and directions are superposed to generate the random water surface. For a directional wave, the instantaneous random surface elevation $\eta_{\mathrm{r}}(\mathrm{t})$ at a point in space such as $(\mathrm{X}, \mathrm{Y})=(0,0)$ is defined as follows:

$\eta_{r}(t)=\sum_{m=1}^{M} \sum_{n=1}^{N}\left(a_{m, n} \cos \left(\omega_{n} t\right)+b_{m, n} \sin \left(\omega_{n} t\right)\right)$

where $a_{m, n}$ and $b_{m, n}$ are Fourier components, which are independent Gaussian random variables with a zero mean and a variance related to the wave energy spectrum at the corresponding discrete frequency and direction as follows:

$\sigma_{\eta \eta, m, n}^{2}=S_{\eta \eta}\left(\omega_{n}\right) d \omega \cdot D\left(\theta_{m}\right) d \theta$

The directional constrained surface elevation $\eta_{c}(t)$ is considered as follows:

$\eta_{c}(t)=\eta_{r}(t)+r(t)\left[\alpha-\sum_{m=1}^{M} \sum_{n=1}^{N} a_{m, n}\right]+\left(\frac{-\dot{r}(t)}{\lambda^{2}}\right)\left[\dot{\alpha}-\sum_{m=1}^{M} \sum_{n=1}^{N} \omega_{n} b_{m, n}\right]$
(a)
(b) (c)
(d)
(e) (f)
(g)

where the terms have the following meanings:

term (a) - the original random surface elevation;

term (b) - the unit NewWave surface elevation ( $\eta(t)$ when $\alpha=1$, see [4] and [17]); 
term (c) - the predetermined constrained crest height $(\alpha)$;

term (d) - the original random surface elevation at $t=0$ (or $\left.\eta_{r}(0)\right)$;

term (e) $-\dot{r}(t)$ is the slope of the unit NewWave; $\lambda^{2}$ is obtained from the second spectral moment of the wave energy spectrum $\left(\mathrm{m}_{2}=\lambda^{2} \sigma^{2}\right)$;

term (f) - the predetermined constrained slope; for a crest, $\dot{\alpha}=0$;

term (g) - the slope of the original random surface at $t=0$ (or $\left.\dot{\eta}_{\mathrm{r}}(0)\right)$.

The 2D NewWave and CNW can be generated considering the number of wave propagation direction of one (M $=1$ ) in the above equations. More detailed descriptions of simulating NewWave and CNW can be found in Cassidy [4], Cassidy et al. [14, 15], Tromans et al. [16] and Taylor et al. [17].

In this study, the storm condition is represented by a JONSWAP spectrum with significant wave height $\mathrm{H}_{\mathrm{s}}=17.46 \mathrm{~m}$, peak period $\mathrm{T}_{\mathrm{p}}=17.22 \mathrm{~s}$ and $\gamma=4.1$ (representing a sample Northern North Sea conditions) which is discretized to 1024 frequency components with the cut-off frequency of $4 f_{p}$, where $f_{p}$ is the peak frequency of the spectrum. The duration of the NewWave and CNW is $300 \mathrm{~s}$ and the peak occurs at $\mathrm{t}=150 \mathrm{~s}$. The integration time-step (time increments) in the time domain simulation is $0.1 \mathrm{~s}$, which is less than $1 / 20$ of the zero upcrossing period of the sea-state and 1/20 of the first mode's natural period of the structure [24]. The waves are considered the only environmental load with no applied wind or current. A code is developed to quantify the water surface elevation. The generated water surface elevation is discretised into a finite set of wave components using the Fast Fourier Transform. Each component is expressed using a harmonic wave with a given amplitude, angular frequency, phase angle and a wave direction angle. USFOS uses these components to model the linear water surface and wave kinematics along any structural member. For wave components in a time-history analysis, all of the water particle kinematics are calculated using the Wheeler stretching method [25]. The extended Morison equation [26], which incorporates the relative motions, is used to compute the hydrodynamic forces on a structural element. The hydrodynamic coefficient values for tubular sections in Morison equation are $C_{D}=0.7$ and $C_{M}=2.0$, and the effects of marine growth are not considered. Though it is noted that, because of the truss legs of jack-ups the hydrodynamic coefficients can vary with wave direction, this was not considered in this study. In addition, the possible difference in drag coefficient of due to $2 \mathrm{D}$ and 3D waves was not included. The coefficients were assumed constant so as to investigate directly the effect of the directional wave kinematics.

To explore the effect of wave spreading, the water surface elevation and kinematics are estimated for both two and three-dimensional cases. For 3D analyses, the directional-spreading function $\mathrm{D}(\theta)$ with $\mathrm{s}=4$ (as depicted in 
Figure 2) and $d \theta=5^{\circ}$ are used. For the 2D analyses, based on ISO [27], the reduction in global hydrodynamic actions due to directional spreading can be included by reducing the wave kinematics by an equivalent kinematics reduction factor $\left(\mathrm{K}_{\mathrm{rf}}\right)$. The $\mathrm{K}_{\mathrm{rf}}$ is estimated from Equation 7 by summation of the components of the kinematics from all directions, in-line with mean wave direction and is equal to 0.905 for the spreading function presented in Figure 2. This factor calibrates the kinematics of 2D waves with 3D waves kinematics for the mean wave direction at the location of maximum crest height.

$$
\mathrm{K}_{\mathrm{rf}}=\int_{\bar{\theta}-\frac{\pi}{2}}^{\bar{\theta}+\frac{\pi}{2}} \mathrm{D}(\theta) \cdot \cos (\theta-\bar{\theta}) \mathrm{d} \theta
$$

In this study, both 2D, i.e., unidirectional wave with kinematics reduction factor, and 3D waves are applied on the structure, and the results are compared. Figure 3 and Figure 4 show the water surface profiles, which were computed using the NewWave and CNW models, respectively. In these figures, both 2D and 3D water surfaces are illustrated to provide insight into the characteristics of the two wave models.

\subsection{Nonlinear Structural Modelling}

The USFOS model of the jack-up, which is shown in Figure 1, comprises of three legs and a hull structure. Because the jack-up structural elements are expected to experience substantial deformation and displacement under the action of extreme environmental loading, the jack-up legs are modelled through specially developed beam elements that can simulate large displacements and deformations. The hull structure is also represented by equivalent linear beam elements. The material nonlinearity is modelled using a stress-resultant plasticity approach, where the kinematic hardening model is used to characterise the yield and plastic potential functions $[1,23]$. Geometrical nonlinearities at the local level (i.e., individual members) and global level are considered by updating the structure geometry as the analysis proceeds [1, 23].

\subsection{Soil-Structure Interaction Modelling}

In the jack-up structure, spudcans represent the foundations of the structure and transfer the force on the jack-up legs to the underneath soil. For the sample jack-up analysed here sand conditions were assumed at the seabed, leading to use of a model that assumes drained soil behaviour (equally an undrained clay model could have been used, though this would have led to different failure conditions, with differences explained in Cassidy et al. [28]). To ensure that these foundations perform effectively during storm conditions, the spudcans must endure a preloading process prior to operation commencement. Consequently, during the installation of the jack-ups, the spudcan foundations are preloaded by elevating the hull above the sea surface and filling the ballast tanks in the hull with seawater, which provides a greater vertical load than their proportion of the self-weight of the jack-up. 
The preload level is determined from the required soil-bearing capacity for the design load conditions. During preloading, the spudcan penetrates the seabed until a balance between the total applied load and the soil resistance is attained. After the preload is held for a specific time, the preload water is dumped, and the jack-up is ready to be elevated to the operating air gap. The preloading process provides insight into the vertical bearing capacity of the foundation and can significantly affect the dynamic performance of the jack-up subjected to subsequent environmental loading. However, during storm conditions, the soil underneath the spudcan foundation is subjected to a combination of vertical (V) and horizontal (H) loads and an overturning moment (M). Hence, the soil-spudcan model should incorporate these actions.

In the present study, a hardening plasticity model available in USFOS is used to model the soil-spudcan interaction [29]. This model consists of a yield function to evaluate the bearing capacity and a flow rule to calculate the plastic deformations. The yield function $\mathrm{f}\left(\mathrm{V}, \mathrm{H}, \mathrm{M}, \theta_{\mathrm{p}}\right)$ for this model depends on the resultant horizontal and vertical loads and the bending moments in the 3D model $(\mathrm{H}, \mathrm{V}$ and $\mathrm{M})$ and the corresponding plastic rotation $\left(\theta_{\mathrm{p}}\right)$ of the spudcan, as presented in Equation 8. The function is based on a two-surface concept: the initial yield surface $\left(\mathrm{f}_{\mathrm{e}}\right)$ and the failure surface $\left(\mathrm{f}_{\mathrm{u}}\right)$. The initial yield surface defines the loading condition for which plastic deformation is negligible and the response remains fully elastic, whereas the failure surface represents the fully plastic deformation condition. In the intermediate loading condition (i.e., where $f_{e}<f<f_{u}$ ), the rotational response becomes nonlinear, but sliding and further penetration do not occur [30].

A hardening function $\Gamma$ provides a smooth transition from the initial yield surface to the failure surface in the intermediate zone, which is a function of the plastic rotation of the spudcan such that the zero plastic rotation gives $\mathrm{f}=\mathrm{f}_{\mathrm{e}}$ and $\mathrm{f}=\mathrm{f}_{\mathrm{u}}$ when no plastic capacity remains. Using $\bar{\theta}_{\mathrm{p}}$ as the parameter for the onset of failure, which can be expressed in the form of the spudcan's elastic rotational stiffness, the yield function for sand is presented as follows:

$f\left(V, H, M, \theta_{p}\right)=f_{e}+\left(f_{u}-f_{e}\right) \Gamma$

where

$$
\begin{aligned}
& \mathrm{f}_{\mathrm{e}}=\sqrt{\left(\frac{\mathrm{M}}{0.1875 \mathrm{~V}_{\mathrm{p}} \mathrm{D}_{\text {eff }}}\right)^{2}+\left(\frac{\mathrm{H}}{\mathrm{V}_{\mathrm{p}}}\right)^{2}}-0.48\left(\frac{\mathrm{V}}{\mathrm{V}_{\mathrm{p}}}\right)\left(1-\left(\frac{\mathrm{V}}{\mathrm{V}_{\mathrm{p}}}\right)\right) \\
& \mathrm{f}_{\mathrm{u}}=\sqrt{\left(\frac{\mathrm{M}}{0.625 \mathrm{~V}_{\mathrm{p}} \mathrm{D}_{\text {eff }}}\right)^{2}+\left(\frac{\mathrm{H}}{\mathrm{V}_{\mathrm{p}}}\right)^{2}}-0.48\left(\frac{\mathrm{V}}{\mathrm{V}_{\mathrm{p}}}\right)\left(1-\left(\frac{\mathrm{V}}{\mathrm{V}_{\mathrm{p}}}\right)\right)
\end{aligned}
$$


$\Gamma=\left\{\begin{array}{cl}0 & \text { for } \theta_{\mathrm{p}}=0 \\ 0<\Gamma<1 & \text { for } 0<\theta_{\mathrm{p}}<\bar{\theta}_{\mathrm{p}} \\ 1 & \text { for } \theta_{\mathrm{p}} \geq \bar{\theta}_{\mathrm{p}}\end{array}\right.$

and where $V_{p}$ is the vertical preload, $D_{\text {eff }}$ is the effective spudcan diameter (this is equal to the diameter for purely circular spudcans or the equivalent diameter producing the same planar area for irregular spudcan shapes), and with the explicit form of $\Gamma$ provided in references [29, 30].

Consistent with plasticity theory, the plastic displacements are calculated by differentiating the plastic potential function (g) with respect to their conjugate load (i.e. flow rule). For sand, the plastic potential function is as follows:

$\mathrm{g}=\mathrm{g}_{\mathrm{e}}+\left(\mathrm{g}_{\mathrm{u}}-\mathrm{g}_{\mathrm{e}}\right) \Gamma$

$\mathrm{g}_{\mathrm{e}}=\sqrt{\left(\frac{\mathrm{M}}{0.1875 \mathrm{~V}_{\mathrm{p}} \mathrm{D}_{\text {eff }}}\right)^{2}+\left(\frac{\mathrm{H}}{\mathrm{V}_{\mathrm{p}}}\right)^{2}}-0.32\left(\frac{\mathrm{V}}{\mathrm{V}_{\mathrm{p}}}\right)\left(0.5-\left(\frac{\mathrm{V}}{\mathrm{V}_{\mathrm{p}}}\right)\right)$

$\mathrm{g}_{\mathrm{u}}=\sqrt{\left(\frac{\mathrm{M}}{0.625 \mathrm{~V}_{\mathrm{p}} \mathrm{D}_{\text {eff }}}\right)^{2}+\left(\frac{\mathrm{H}}{\mathrm{V}_{\mathrm{p}}}\right)^{2}}-0.32\left(\frac{\mathrm{V}}{\mathrm{V}_{\mathrm{p}}}\right)\left(0.5-\left(\frac{\mathrm{V}}{\mathrm{V}_{\mathrm{p}}}\right)\right)$

where $g_{e}$ and $g_{u}$ are the initial and failure potential functions, respectively. Detailed information about the hardening plasticity models is presented by Amdahl et al. [29] and Van Langen et al. [30].

\section{RESULTS AND DISCUSSION}

Results from nonlinear dynamic analyses on the sample jack-up structure subjected to extreme sea condition are studied in this section. In this study, the horizontal deck displacement at the hull centre in-line with the mean wave direction is used to represent the effects of the random background of ocean waves fandomness-and wave spreading on the overall nonlinear performance of jack-up structures under dynamically applied extreme waves. Furthermore, the spudcan deformation, which represents the soil nonlinearity, is assessed to explore the effects of random directional waves on the soil plastic deformations as a critical factor that governs the overall performance of jack-up units. The effect of wave-attacking angles on the response of the sample jack-up platform is also investigated. Analyses are performed for mean wave directions of $0,15,30,45$ and $60^{\circ}$ (as presented in Figure 1), and the results are extended to $360^{\circ}$ because the jack-up structure is symmetric about three axes. The $0^{\circ}$ wave attacking angle represent the waves that first attack two windward legs simultaneously 
and subsequently one leeward leg, whereas $60^{\circ}$ wave attacking angle corresponds to the waves that first attack one windward leg and subsequently two leeward legs simultaneously.

\subsection{Results from the NewWave Model}

Shown in Figure 5 is the response of jack-up to a $20 \mathrm{~m}$ 3D NewWave focussed in the centre of the jack-up (at time $=150 \mathrm{~s}$ ) and attacking the platform from an angle of $0^{\circ}$. The maximum deck displacement is $3.02 \mathrm{~m}$ and occurs just after the maximum crest travels through. A comparison of the deck displacements for the same $20 \mathrm{~m}$ NewWave focussed (i) at the leeward leg and (ii) at the windward legs is also shown in Figure 5. The results confirm, for this sample jack-up and wave conditions, the peak wave focussed at the centre of the jack-up as being the largest response. For the remainder of the paper this central hull location is the focal point of the NewWave crest. This also has the advantage, for the symmetric sample jack-up being analysed, of producing symmetric NewWave loading conditions (and thus response) every $120^{\circ}$ of rotation of the wave attack angle.

Figure 6 represents the maximum deck displacement of the sample jack-up against NewWaves with a maximum crest height of $20 \mathrm{~m}$ focussed at the hull centre, but approaching from different angles. It is a large wave which leads to severe nonlinearity in soil and structural components. The inner envelope shows the maximum predicted deck displacement of the 3D NewWave model, whereas the outer envelope represents the same results of the 2D NewWave model. The inclusion of 3D effects apparently decreases the horizontal deck displacement in all wave-attacking directions.

To better understand how the inclusion of the wave directionality can cause such considerable changes in the results, the response of the sample jack-up when subjected to waves from $0^{\circ}$ are further investigated as an example. Figure 7 and Figure 8 present the time histories of the deck displacement at the reference node (i.e., the centre on the hull) and at the leeward spudcan, respectively. In these figures, points "a" and "c" correspond to the results of 3D and 2D waves, respectively, when a wave crest passes through the structure, and points "b" and "d" correspond to the time when a wave trough passes through the sample jack-up.

As observed in Figure 7, the maximum deck displacement because of the crest of the 3D NewWave (point "a") is considerably less than that of 2D NewWave crest (point "c"). In other words, the inclusion of wave spreading reduces the maximum deck displacement when a wave crest passes through the sample jack-up model. This result is completely consistent with the reduction in the horizontal and vertical displacements in the leeward spudcan from point "c" to point "a" as presented in Figure 8. It is worth noting that the reduction in spudcan vertical displacement, which is a result of including the 3D effects, can delay or prevent the global instabilities during storms. To explore such results, the time histories of the NewWave water surface at the windward legs, 
leeward leg and reference node at the jack-up hull (Figure 9) are investigated. Figure 9 shows that the $20 \mathrm{~m}$ crest height occurs at the reference node of the jack-up in both the 2D and 3D cases (as this was the input). However, a focus on the water surface profile clearly displays that on the windward legs, the 3D NewWave simulated a smaller crest height than the 2D NewWave. This result shows that in this case study, the inclusion of 3D effects reduces the hydrodynamic forces when a wave crest passes through the structure and explains why this inclusion reduces the displacements at the jack-up hull and leeward spudcan.

Figure 10 traces the hysteresis of resultant forces on the leeward spudcan, which are superimposed to the soilspudcan initial yield and failure surfaces (Equations 9 and 10 in Section 2.3). In this figure, when the hysteretic resultant force becomes asymptotic to the failure surface $\left(f=f_{u}\right.$ ) means that a fully plastic condition occurs. At this stage, the plastic deformations become large, i.e. further penetration or sliding failure starts to occur. Figure 10 shows that for both 2D and 3D NewWaves, when a wave crest passes through the structure, plasticity occurs in the soil (points “a” and "c").

The analyses are repeated with a NewWave with maximum crest height of $17 \mathrm{~m}$ for which no considerable plastic response in the soil is expected. The results from these analyses are plotted in Figure 11, which clearly shows that the inclusion of wave spreading diminishes the amount of deck displacement. However, the rate of reduction in deck displacement because of inclusion of the 3D effects is lower than that when nonlinearity occurs in soil for a crest height of $20 \mathrm{~m}$. Therefore, the effect of wave spreading obviously has a great interdependency with the soil-spudcan-structure interaction. In fact, to rationally assess the effect of the wave directionality, it is crucial to accurately predict the soil-spudcan deformations.

\subsection{Results from the CNW Model}

To inspect the effects of the random background of waves as well as their directionality, 2D and 3D CNWs were generated and applied on the structure. Figure 12 displays the time history of deck displacement of the sample jack-up, which was subjected to a CNW with a NewWave crest height of $20 \mathrm{~m}$ at the hull centre approaching from $0^{\circ}$. The behaviour in this figure is notably similar to the behaviour for NewWave in Figure 7: the inclusion of 3D effects reduces the maximum deck displacement when the wave crest passes through the structure.

Displaying the water surface profile on the jack-up legs can provide more insight into the effect of the directionality of random waves. Figure 13 illustrates the water surface profile on two windward legs. It can be noticed that unlike the 3D NewWave model, the 3D CNW model predicts different water surface elevations on the windward legs, which can cause more out of plane and torsional vibrations in the structure than the model with 3D NewWave. 
To further assess the effect of 3D CNWs, the time history of the deck displacement perpendicular to the mean wave direction is illustrated in Figure 14. It should be noted for the 3D NewWave this value is zero as the summation of perpendicular components of the wave force are zero considering the symmetric structure and symmetric water surface. However, for the 3D CNW, the deck fluctuates in the perpendicular direction (shown in Figure 14) with much smaller amplitude than that observed in the mean wave direction (shown in Figure 12). This indicates that the wave force in the perpendicular direction is not zero which is due to the asymmetric water surface of the 3D CNW. The maximum total deck displacement of 2D and 3D CNWs, are $2.78 \mathrm{~m}$ and $2.62 \mathrm{~m}$ respectively.

To assess the effect of different random backgrounds of CNWs on the structural response statistics, 100 2D and 100 3D CNWs with a NewWave crest height of $17 \mathrm{~m}$, positioned at the hull centre, were generated and applied on the sample jack-up. It is noticed that no overall failure occurred under the applied CNWs. The statistical results extracted from these analyses can be characterised using the Weibull distribution function [31]. Figure 15 depicts the Weibull distribution of the maximum computed deck displacements using 100 analyses for 3D CNWs approaching from $0^{\circ}$. The Weibull distributions of the maximum deck displacement from 2D and 3D CNWs are compared in Figure 16. In addition, Figure 17 plots the mean values of the Weibull distribution of the maximum deck displacement from 2D and 3D CNWs with a NewWave crest height of $17 \mathrm{~m}$, which attacks from different directions. These figures demonstrate that the inclusion of wave spreading can considerably change the response statistics.

\subsection{Effect of Wave Spreading on the Probability of Failure}

The analyses results for NewWaves with maximum crest heights of $17 \mathrm{~m}$ and $20 \mathrm{~m}$ and for 100 CNWs with a NewWave crest height of $17 \mathrm{~m}$ demonstrate that these waves do not lead to any failure in the sample jack-up. However, when the jack-up is subjected to CNWs with a crest height of $20 \mathrm{~m}$, it cannot survive the attack from some of these random waves. Table 1 summarises the total number of failures for different wave-approaching directions and the modes of failure for 2D and 3D CNWs. The probability of failure is calculated by dividing the number of failure cases to the total number of analyses for each direction (i.e., 100 cases).

It is worth highlighting that the failure modes mainly occur because of either foundation failure (i.e., punchthrough failure) or a loss of overturning stability (i.e. spudcan uplift), which is expected for the amount of applied preload of $80 \mathrm{MN}$ [32]. The maximum number of failures occurs for the wave-attacking angle of $60^{\circ}$, where all failure modes are unstable in the structure because of overturning. 
In Figure 18, the probability of failure in different wave directions is overlaid for both 2D and 3D CNW analyses. This figure demonstrates that for the sample jack-up, the inclusion of wave spreading reduces the probability of failure due to the random background in the CNWs that approach from different directions. The results reflect that the governing mode of failure differs as the wave direction is altered. There is a compressive punching failure in the single leeward leg in the $0^{\circ}$ wave direction. Once the wave has rotated to the $60^{\circ}$ wave direction there is a single windward leg and it fails due to spudcan uplift. These two conditions have higher probabilities of failure than the angles in-between as they represent the failure of the one leg.

\subsection{Effect of Wave Spreading and the Random background on the Dynamic Amplification Factor (DAF)}

When the randomness and wave-spreading effects are included in the analysis, the structure is excited from different directions with different frequency contents. Therefore, it is productive to evaluate the dynamic amplification factor (DAF) when these effects are included.

The dynamic effects from the wave loads may be assessed based on comparing the significant response obtained from both a dynamic analysis and a quasi-static analysis. The displacement of the hull centre in the mean wave direction may be typically chosen as the response variable to determine DAF [33] as it is shown in Equation 15.

$\mathrm{DAF}=\frac{\mid \text { Maximum dynamic hull displacement } \mid}{\mid \text { Maximum static hull displacement } \mid}$

To illustrate the efficiency of the deck displacement in comparison to a base shear as the response variable to estimates the DAF, dynamic and quasi-static analyses were performed with 3D NewWaves with maximum crest heights of $17 \mathrm{~m}$ and $20 \mathrm{~m}$, and the DAF was estimated based on both the deck displacement and the base shear. It is observed that for the crest height of $17 \mathrm{~m}$, the calculated DAF based on the deck displacement is 1.397, but decreases to 1.389 when estimated based on the base shear, as shown in Figure 19. This reduction is more pronounced for the 20 m crest height, where the displacement DAF is 1.268 and the base shear DAF is 1.208. As previously stated in Section 3.1, under NewWave with a crest height of $20 \mathrm{~m}$, nonlinearities occur in the soilspudcan; however, the effect of these nonlinearities in the overall response is not reflected in the base shear. Therefore, a higher amount of plasticity in the system results in a higher difference between the estimated DAFs from the base shear and the deck displacement. It is also noted that when the crest height is increased from $17 \mathrm{~m}$ to $20 \mathrm{~m}$, the DAF is decreased, which is attributed to the plastic deformations in soil, which reduces the effect of dynamic actions.

To assess the effect of wave spreading on the DAF, the results from 2D and 3D NewWaves are compared with the average results of 100 2D and 3D CNWs with a crest height of $17 \mathrm{~m}$, which approach from different angles, 
as depicted in Figure 20. In this figure, the 2D waves estimated different DAFs from the 3D waves. However, there is no general trend that rules such changes, i.e., 2D waves do not always result in a higher DAF. It should be noted that inclusion of a random background considerably increases the DAF for both 2D and 3D CNWs in comparison with the NewWaves.

\subsection{Effect of Different Wave Periods on Wave-spreading}

In order to assess the effect of wave period on the wave-spreading effects, two other wave spectrums (JONSWAP spectrum) with significant wave heights of $H_{s}=12.00 \mathrm{~m}$ and $14.40 \mathrm{~m}$ and peak wave periods of $T_{p}$ $=12.86 \mathrm{~s}$ and $15.21 \mathrm{~s}$ respectively and $\gamma=3.3$ with cut-off frequencies of $4 \mathrm{f}_{\mathrm{p}}$ which are discretized to 1024 frequency components are considered. 100 2D and 3D CNWs with maximum crest heights of $17 \mathrm{~m}$ and $20 \mathrm{~m}$ are generated and applied on the same sample jack-up structure. Figure 21 shows the ratio of the mean values of the Weibull distribution of the maximum deck displacement of 3D to 2D for the $100 \mathrm{CNWs}$. This is for a constrained crest height of $17 \mathrm{~m}$ (at the hull centre) and compares different wave periods attacking from different directions. As presented in Figure 21, for this sample jack-up's dimensions when the wave period decreases the difference between 3D and 2D responses increases. This is because the crest width (perpendicular to the mean wave direction) of the 3D waves decreases with a lower wave period. Therefore, the effect of wavespreading effect is more pronounced.

Figure 22 compares the ratio of the average DAF of 3D CNWs to that of 2D CNWs (again for a crest height of $17 \mathrm{~m}$ constrained at the hull centre). This ratio increases as the wave period decreases (and is particularly pronounced for $T_{p}=12.86 \mathrm{~s}$ ). It shows that, for the sample jack-up, when the peak wave period approaches the natural period of the structure then the effect of waves that are exciting the structure from different directions is more significant. This is because the dynamic effects are making a greater contribution.

Figure 23 depicts the difference in the probability of failure of the sample jack-up for 2D and 3D waves. As illustrated, when the sample jack-up platform is subject to waves with lower periods (approaching the natural period of the jack-up) inclusion of 3D effects results in a decrease in the failure rate. This is because of the narrower crest width due to a lower period as well as the high nonlinearities in soil from the $20 \mathrm{~m}$ crest height. As previously discussed in section 3.1, the difference between 2D and 3D results will be greater when a larger crest height, which results in higher nonlinearity in the soil, passes through the structure.

\subsection{Wave Spreading and Fatigue Life Time of Offshore Structures}

In the current provisions, the fatigue life of offshore structures was evaluated by applying deterministic and spectral methods, where the wave analyses were conducted using $2 \mathrm{D}$ and regular wave theories. To assess the 
effects of wave spreading on the fatigue life of a jack-up structure, 2D and 3D NewWaves with a crest height of $5 \mathrm{~m}$ were generated from a sea-state characterised by a Pierson-Moskowitz spectrum with $\mathrm{H}_{\mathrm{s}}=4.75 \mathrm{~m}$ and $\mathrm{T}_{\mathrm{p}}=$ $11.5 \mathrm{~s}$ with the cut-off frequency of $4 \mathrm{f}_{\mathrm{p}}$ using the spreading function in Figure 2 and applied on the sample jackup platform. The Pierson-Moskowitz spectrum was used in this case to be consistent with the DNV [33] guidelines. The spectrum is discretized to 1024 frequency components and $\mathrm{d} \theta$ is equal to $5^{\circ}$.

Figure 24 presents the axial force developed in a brace member near the water surface as an example. The inclusion of 3D effects clearly reduces the internal forces. Based on the results from this high-level study, it can be concluded that the inclusion of spreading can change the internal actions in the members and connections and potentially affect the fatigue life of offshore structures. Note that this result was based on a narrow spreading function ( $\mathrm{s}=4$ in Figure 2), whereas fatigue waves (i.e., waves that result in high fatigue damage) usually have a wider spreading function [34], which clearly intensifies the wave directionality effects. Therefore, further investigation is recommended on this subject.

\section{SUMMARY AND CONCLUSIONS}

In this paper, NewWave and CNW theories were used to determine the sea-state to investigate the effects of wave directionality and the random nature of ocean waves on the performance of a sample jack-up platform, as an example of a dynamically sensitive structure. Both 2D, i.e., unidirectional wave with kinematics reduction factor, and 3D waves are applied on the structure, and the results are compared.

In this study linear waves with linear wave kinematics were employed. However, it should be noted that using a second order water surface and kinematics model ean-may cause different results. In addition, it is acknowledged that results ean-may vary if a different spreading function such as frequency dependent function is adopted. Based on the results outlined in this paper, the following points are highlighted for the sample jackup:

- The inclusion of wave spreading in dynamic analyses reduces the maximum deck displacement for all wave-approaching angles. The results from both the NewWave and CNW models with different periods confirm this behaviour.

- The level of reduction in the maximum deck displacements due to inclusion of wave 3D effects depends on the wave period as well as the level of nonlinearity in the structure and soil-spudcan interactions, such that by decreasing the wave period and/or by increasing soil plasticity the 3D effects become more pronounced. 
- $\quad$ The evaluation of the results shows that the 2D CNWs lead to a considerably higher failure rate than the 3D CNWs. Thus, when the 3D spreading effects are included, the probability of failure is noticeably decreased. In addition, it is shown that the level of reduction in the failure probability is increased when wave period is decreased.

- $\quad$ The DAF that is estimated based on the ratio of the maximum base shear from a dynamic analysis to the maximum base shear from a quasi-static analysis is generally lower than the DAF that is estimated based on the maximum deck displacement because the maximum base shear fails to reflect the effect of nonlinearities in the system.

- Inclusion of the wave-spreading effect changes the DAF. For relatively higher wave periods such change does not follow a general trend, however, when the wave period is decreased, i.e. when wave period approaches the natural period of structure, inclusion of 3D effects results in increase in DAF. The effect of including a random background considerably increases the DAF level for both 2D and 3D CNWs in comparison with the deterministic NewWaves.

- $\quad$ The change in internal actions of the structural members and connections suggests the potential effect of wave spreading on the fatigue life of the jack-up structures or other offshore structures, for which the 3D-wave effects are considerable. Therefore, further investigation is recommended on this subject.

- $\quad$ In this paper comparisons between deterministic NewWaves and NewWaves of the same height and spatial location constrained within 100 different random seas were considered. To account for the full random nature of the ocean, Constrained NewWave methodologies such as Taylor et al. (1997) and Cassidy et al. (2001), could be extended from 2D to 3D to allowing the extreme statistics of a shortterm storm to be evaluated. The 3D Constrained NewWave discussed in this paper could be used for such an extension.

\section{ACKNOWLEDGMENTS}

This study was performed with the support from the Australian Research Council (ARC) Centre of Excellence for Geotechnical Science and Engineering, the ARC Laureate Fellowship scheme and the Lloyd's Register Foundation (LRF). LRF is a UK registered charity and sole shareholder of Lloyd's Register Group Ltd, which invests in science, engineering and technology for public benefit worldwide. This support is appreciated. The helpful advice and comments from Dr. Tore Holmås of USFOS A/S and Prof. Jørgen Amdahl of the Norwegian University of Science and Technology during the course of this study are also appreciated. 


\section{REFERENCES}

[1] Skallerud, B., Amdahl, J. Nonlinear analysis of offshore structures. England: Research Studies Press; 2002.

[2] Schotman, GJM. The effects of displacements on the stability of jackup spudcan foundations. In: Proc. $21^{\text {st }}$ Offshore Technology Conf., Houston, 1989. pp. 515-524, OTC 6026.

[3] Van Langen, H., Hospers, B. Theoretical model for determining rotational behaviour of spud cans. In: Proc. $25^{\text {th }}$ Offshore Technology Conf., Houston, 1993. pp. 399-409, OTC 7302.

[4] Cassidy, MJ. Non-linear analysis of jack-up structures subjected to random waves. University of Oxford, UK; 1999 [D. Phil Thesis].

[5] Bienen, B. and Cassidy, MJ. Three-dimensional numerical analysis of centrifuge experiments on a model jack-up drilling rig on sand. Canadian Geotechnical Journal 2009; 46(2):208-224.

[6] Sharma, JN., Dean, RG. Second-order directional seas and associated wave forces. Society of Petroleum Engineers 1981;129-140.

[7] Dalzell, JF., A note on finite depth second-order wave-wave interactions. Applied Ocean Research 1999; 21:105-111.

[8] Forristall, GZ., Wave crest distributions: observations and second-order theory. Journal of physical oceanography 2000;30(8):1931-1943.

[9] Walker, DAG., Taylor, PH., Eatock Taylor, R., The shape of large surface waves on the open sea and the Draupner New Year wave. Applied Ocean Research 2004; 26:73-83.

[10] Gibbs RH., Taylor, PH. Formation of walls of water in 'fully' nonlinear simulations. Applied Ocean Research 2005; 27:142-157.

[11] Adcock, TAA., Taylor, PH., Estimating ocean wave directional spreading from an Eulerian surface elevation time history. In: Proc. of the Royal Society of London A: Mathematical, Physical and Engineering Sciences 2009; 465:3361-3381.

[12] API. Recommended Practice for Planning, Designing and Constructing Fixed Offshore Platforms-Working Stress Design, RP 2A-WSD, USA, 2010.

[13] Smith, SF., Ahilan, RV., Hoyle, M., Swan, C., Marcom, M. The effects of new developments in wave modelling on jack-up loads. In: Proceedings $20^{\text {th }}$ Int. Conf. on Offshore Mechanics and Arctic Engineering, Rio de Janeiro, 2001. OMAE2001/OFT-1275.

[14] Cassidy, MJ., Eatock Taylor, R., Houlsby, GT. Analysis of jack-up units using a Constrained NewWave methodology. Applied Ocean Research 2001; 23:221-234.

[15] Cassidy, MJ., Taylor, PH., Eatock Taylor, R., Houlsby, GT. Evaluation of long-term extreme response statistics of jack-up platforms. Ocean Engineering 2002; 29(13):1603-1631.

[16] Tromans, PS., Anaturk, AR., Hagemeijer, P. A new model for the kinematics of large ocean wavesapplication as a design wave. In: Proc. 1st Int. Offshore and Polar Engineering Conf., Edinburgh, 1991. pp. 6471.

[17] Taylor, PH., Jonathan, P., Harland, LA. Time domain simulation of jack-up dynamics with the extremes of a Gaussian process. Journal of Vibration and Acoustics 1997; 119(4):624-628.

[18] Cassidy, MJ. Offshore foundation systems for resource recovery: Assessing the three-dimensional response of jack-up platforms. KSCE Journal of Civil Engineering 2011; 15(4):623-634.

[19] Smith, SF., Hoyle, MJR., Ahilan, RV., Hunt, RJ., Marcom, MR. 3D nonlinear wave spreading on jack-up loading and response and its impact on current assessment practice. Offshore Technology Conf., Houston, 2006, OTC 18266.

[20] Hoyle, MJR., Smith, SF., Ahilan, RV., Hunt, RJ., Marcom, MR. Further work on the effects of nonlinear wave spreading and its impact on current jack-up assessment practice. Offshore Technology Conf., Houston, 2009, OTC 20297.

[21] Ewans, KC. Observations of the directional spectrum of fetch-limited waves. Journal of Physical Oceanography 1998; 28:495-512. 
[22] Forristall, GZ., Ewans, KC., Worldwide measurements of directional wave spreading. Journal of Atmospheric and Oceanic Technology 1998; 15:440-469.

[23] Sorehde, T., Amdahl, J., Eberg, E., Hellan, O., Holmås, T. USFOS - A computer program for progressive collapse analysis of steel offshore structures. Theory manual. SINTEF Report STF71 F 88038, 1993.

[24] ABS. Dynamic analysis procedure for self-elevating drilling units, Houston, TX, 2004.

[25] Wheeler, JD. Method for calculating forces produced by irregular waves. Journal of Petroleum Technology 1970; 22(3):359-367.

[26] Chakrabarti, SK., TAM, WA., Wolbert, AL., Wave forces on a randomly oriented tube. In: Proc. Offshore Technology Conf., Houston, 1975. pp. 433-447, OTC 2190.

[27] ISO. Petroleum and natural gas industries - Specific requirements for offshore structures - Part 1 : Metocean design and operating considerations, ISO 19901-1, Switzerland, 2005.

[28] Cassidy, MJ., Martin, CM., Houlsby, GT. Development and application of force resultant models describing jack-up foundation behaviour. Marine Structures 2004; 17(3-4):165-193.

[29] Amdahl, J., Johansen, A., Svan, G. Ultimate capacity of jack-ups considering foundation behaviour. In: Proc. 7th Int. Conf. on the Behaviour of Offshore Structures, Massachusetts, 1994. pp. 347-359.

[30] Van Langen, H., Wong, P., Dean, E. Formulation and validation of a theoretical model for jack-up foundation load-displacement assessment. Marine Structures 1999; 12(4):215-230.

[31] Mirzadehniasar, J., Kimiaei, M., Cassidy, MJ. A framework to efficiently calculate the probability of failure of dynamically sensitive structures in a random sea. Ocean Engineering 2014 [submitted for publication].

[32] Mirzadehniasar, J., Kimiaei, M., Cassidy, MJ. Nonlinear dynamic analysis of jack-up platforms exposed to extreme random waves. In: Proc. $31^{\text {st }}$ Int. Conf. on Offshore Mechanics and Arctic Engineering, Rio de Janeiro, 2012. OMAE2012-83786.

[33] DNV. Self-elevating units, DNV-RP-C104, Norway, 2012.

[34] SNAME. Recommended practice for site specific assessment of mobile jack-up units, Rev. 3. The Society of Naval Architects and Marine Engineers, 2008. 


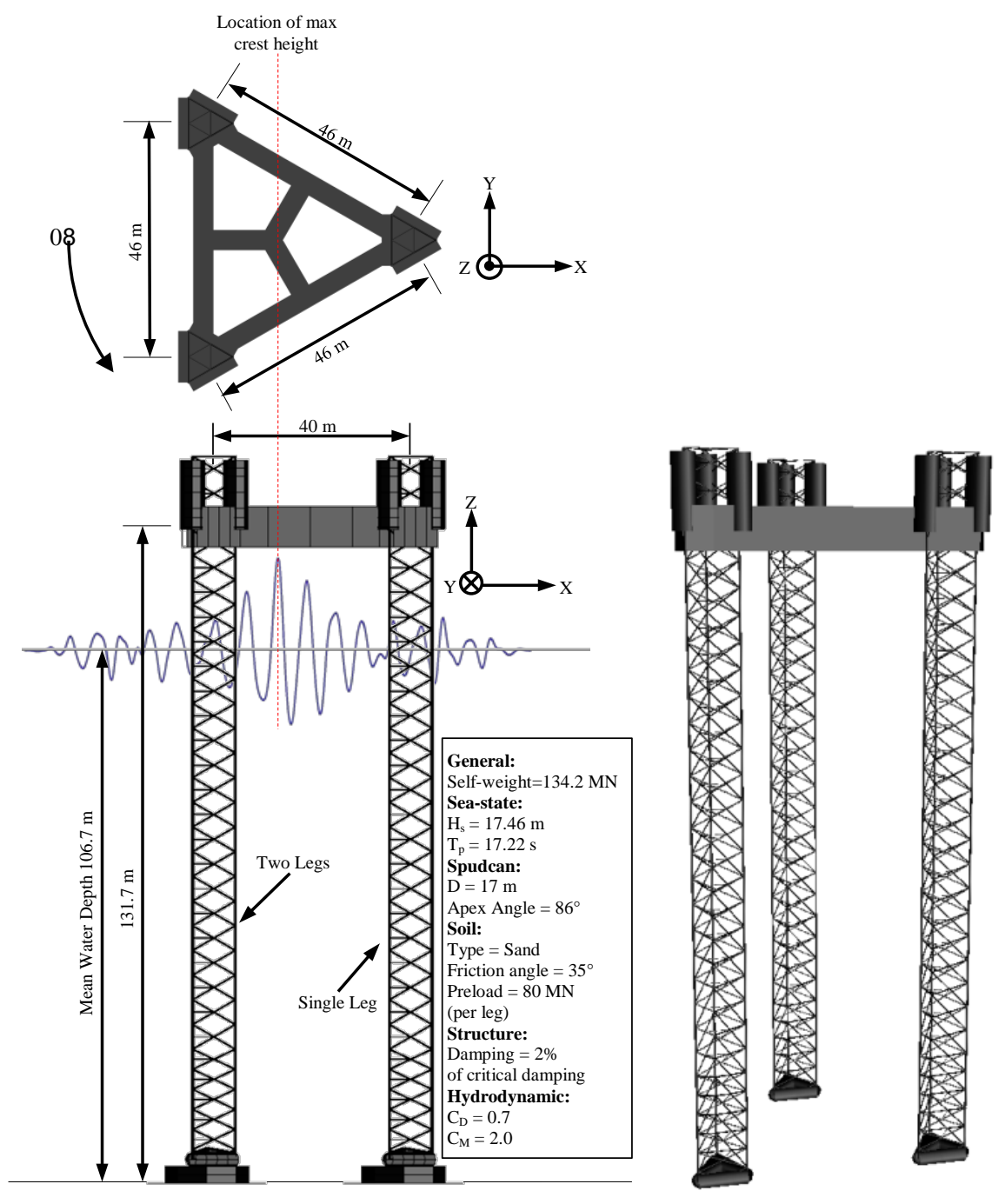

Figure 1. A general view of the sample jack-up platform 


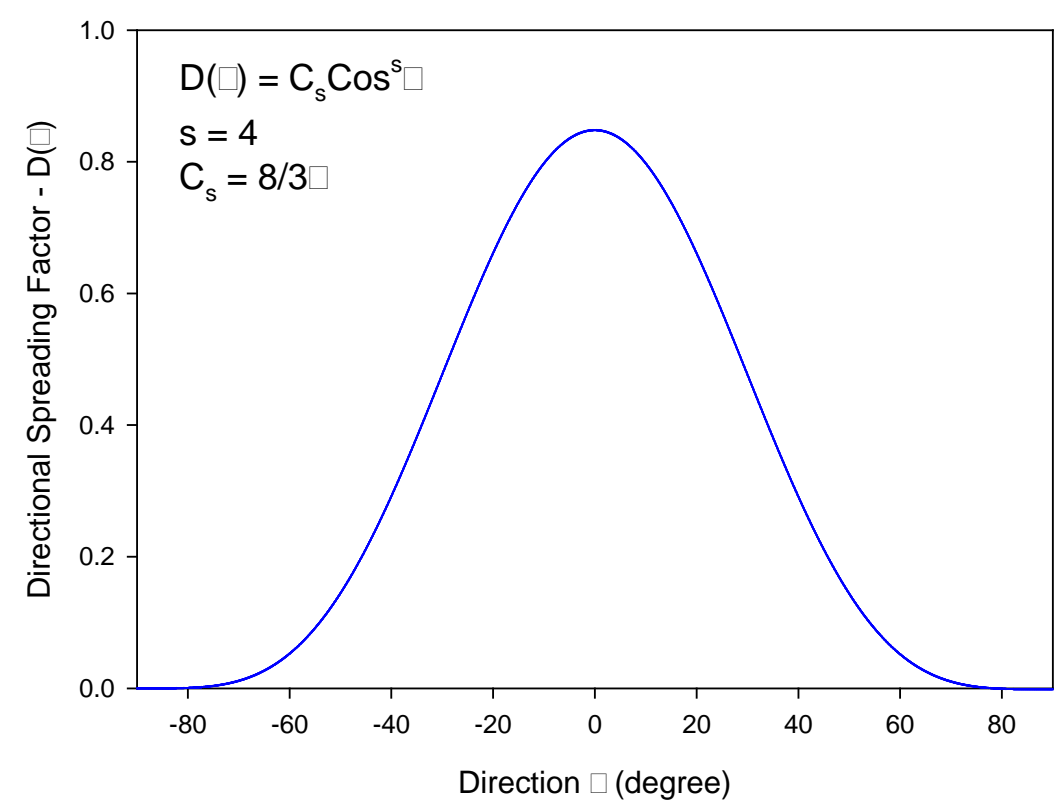

Figure 2. Spreading function
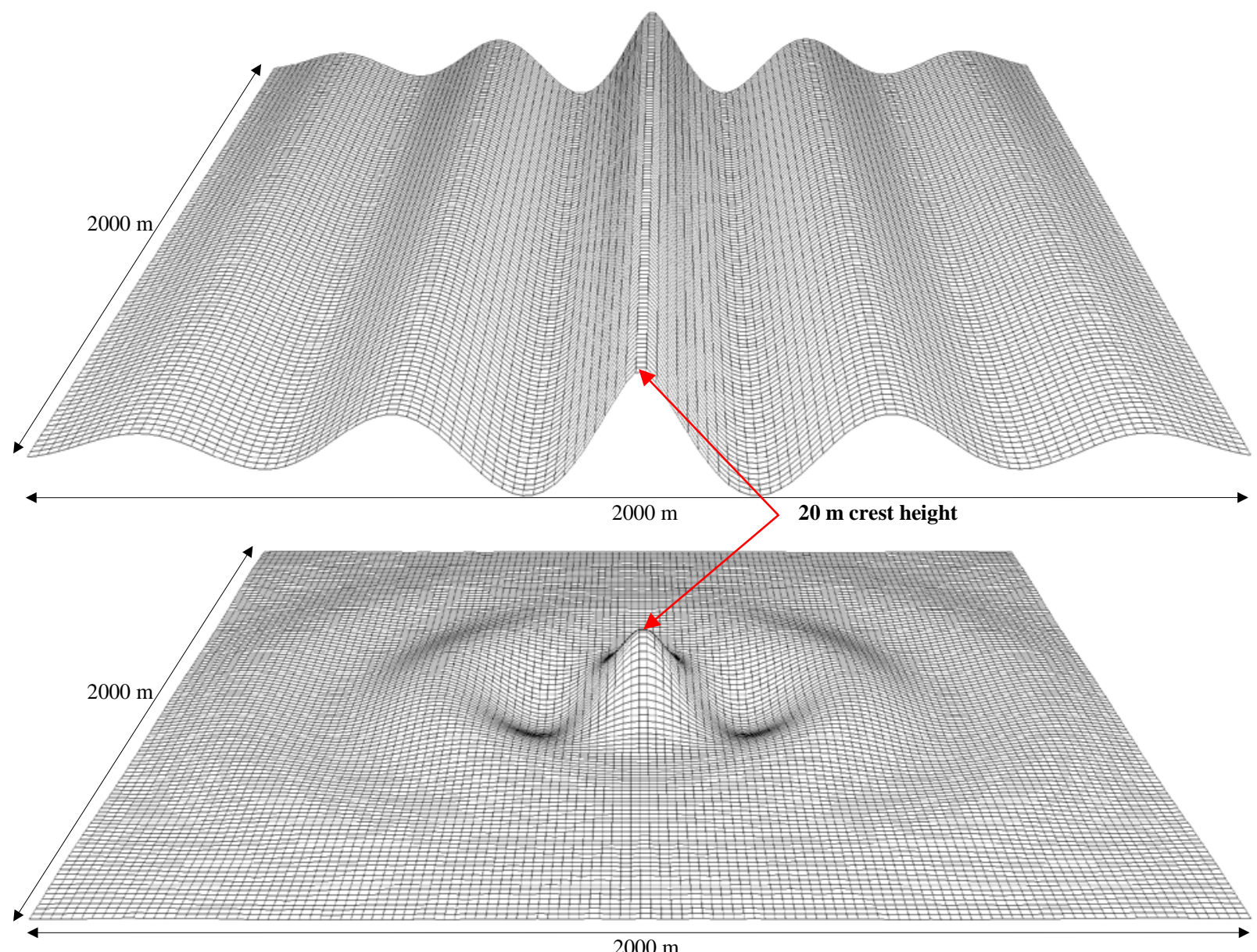

Figure 3. 2D \& 3D NewWave surface profiles - Space plot at $t=150 \mathrm{sec}$, Maximum crest height $=20 \mathrm{~m}$ JONSWAP spectrum with $\mathrm{H}_{\mathrm{s}}=17.46 \mathrm{~m}$ and $\mathrm{T}_{\mathrm{p}}=17.22 \mathrm{~s}$ (Vertical scaling factor $=5$ ) 


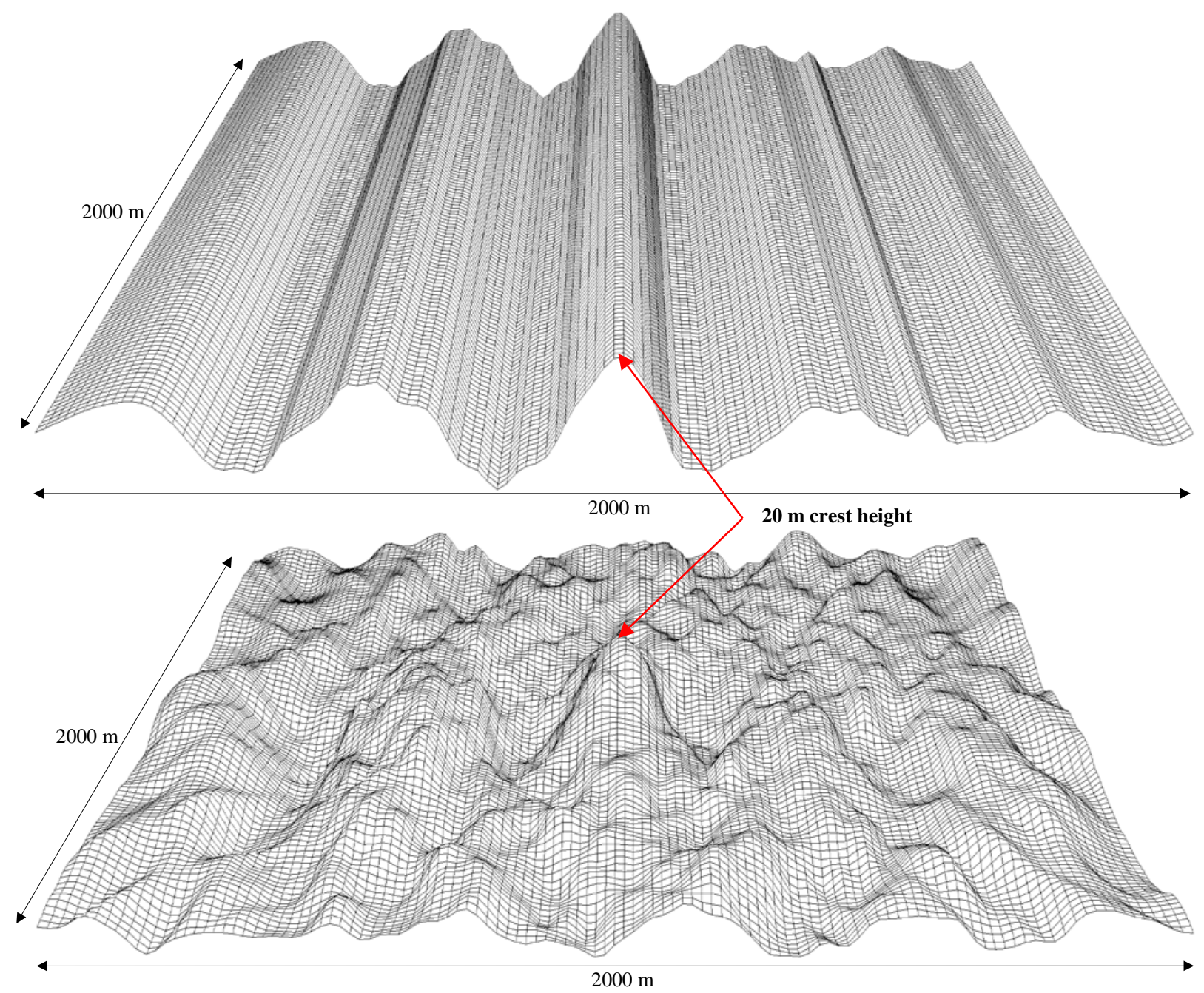

Figure 4. 2D \& 3D CNW surface profiles - space plot at $\mathrm{t}=150 \mathrm{sec}$, Maximum crest height $=20 \mathrm{~m}$ JONSWAP spectrum with $\mathrm{H}_{\mathrm{s}}=17.46 \mathrm{~m}$ and $\mathrm{T}_{\mathrm{p}}=17.22 \mathrm{~s}$ (Vertical scaling factor $=5$ ) 


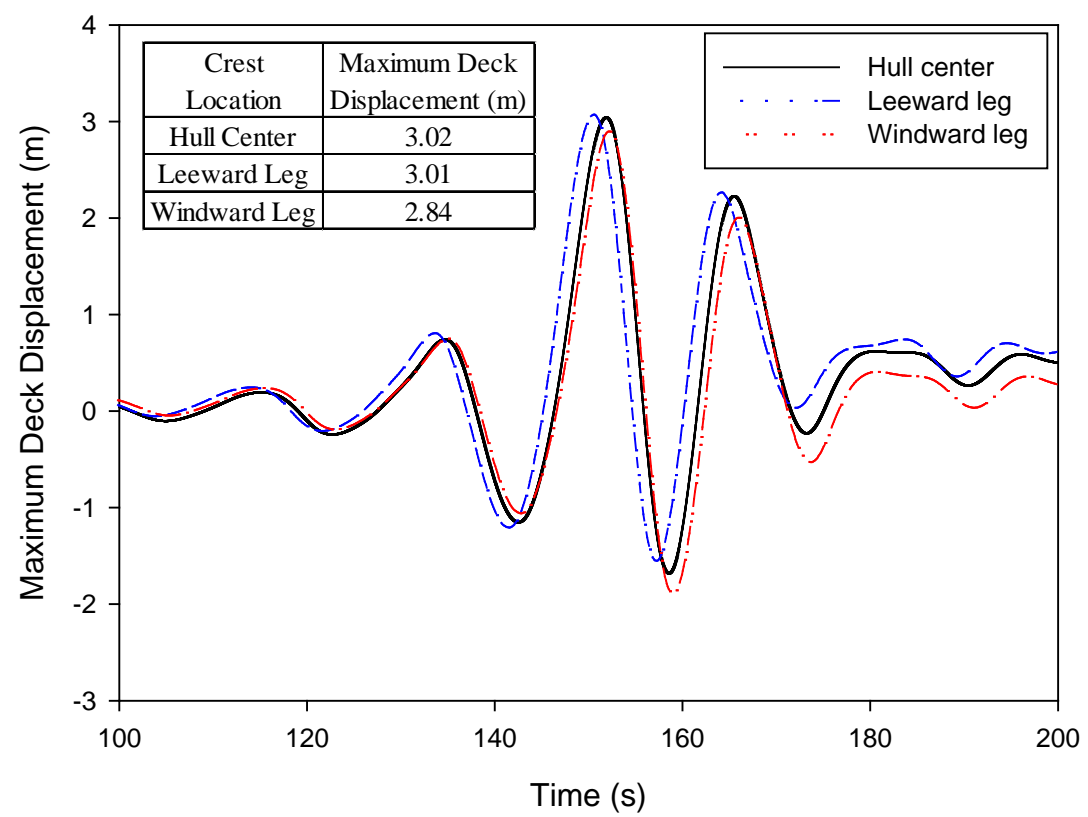

Figure 5. Comparison of the deck displacements for 3D NewWave with $20 \mathrm{~m}$ crest height focussed at different locations 


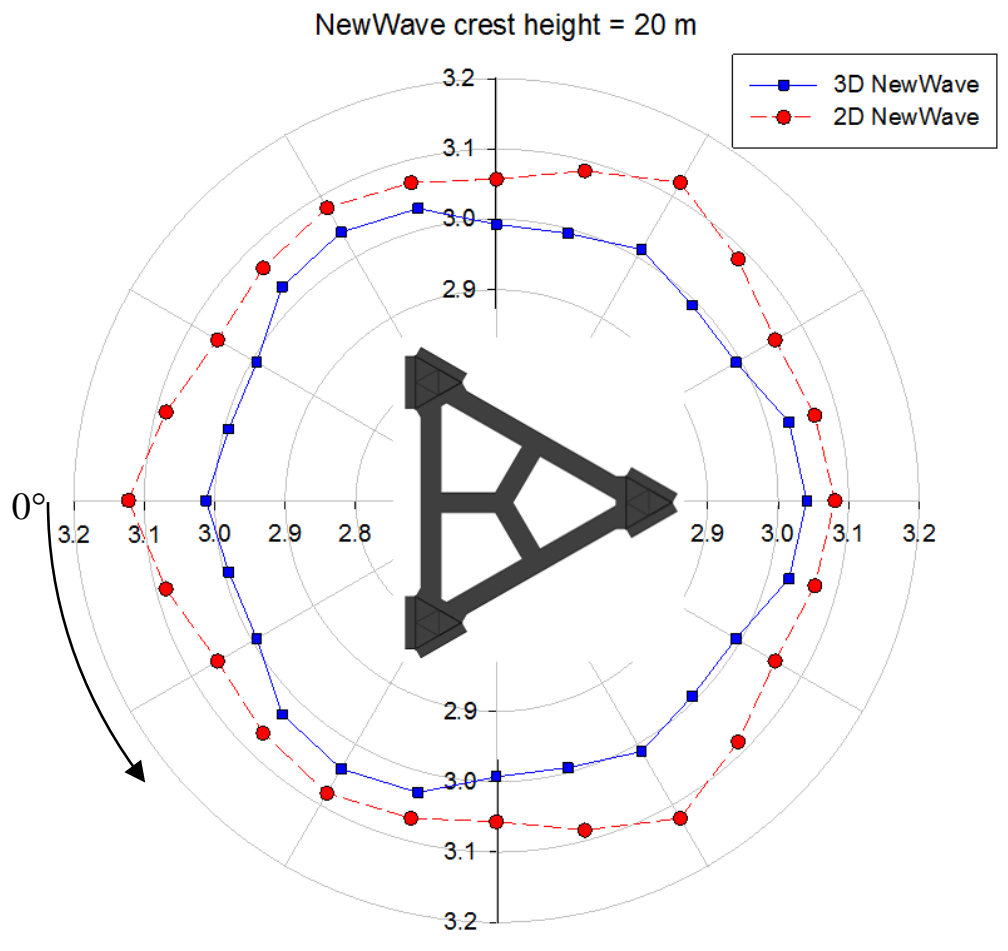

Maximum deck displacement $(\mathrm{m})$

Figure 6. Comparison of the maximum deck displacements for 2D \& 3D NewWaves that have a $20 \mathrm{~m}$ crest height and approach from different directions 


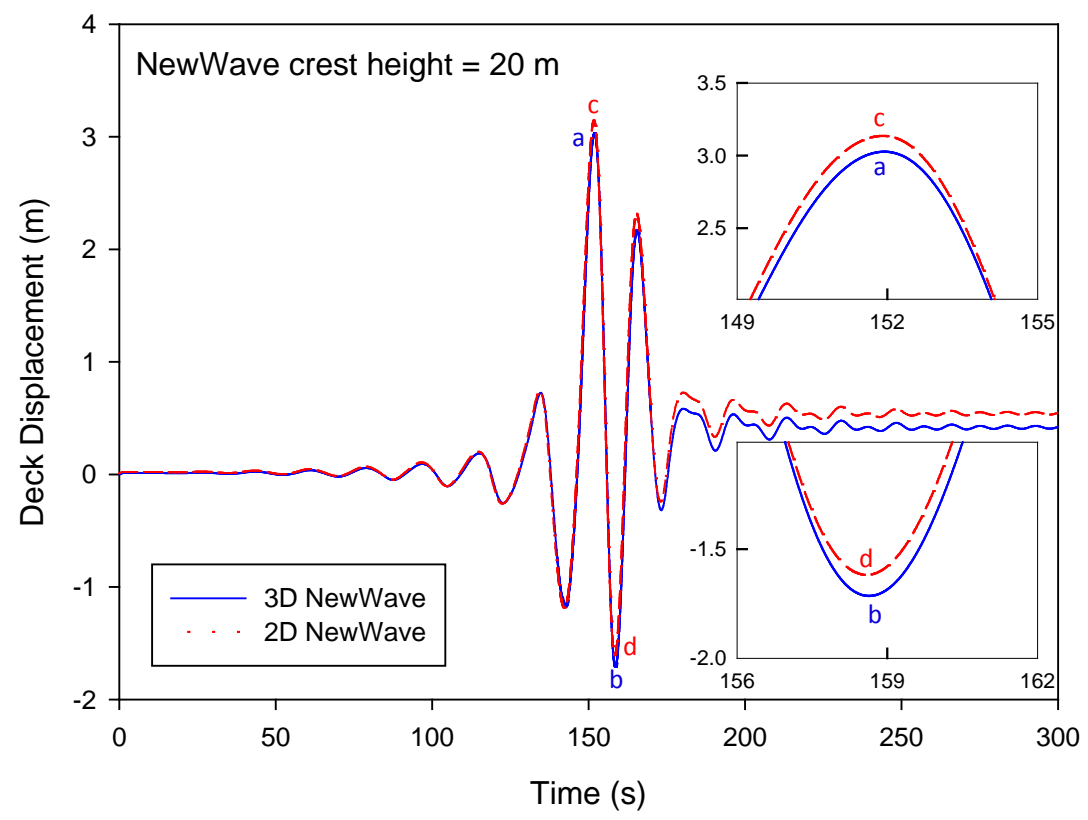

Figure 7. Comparison of the time history of deck displacement of the sample jack-up for 2D \& 3D NewWaves with $20 \mathrm{~m}$ crest height approaching from 08 

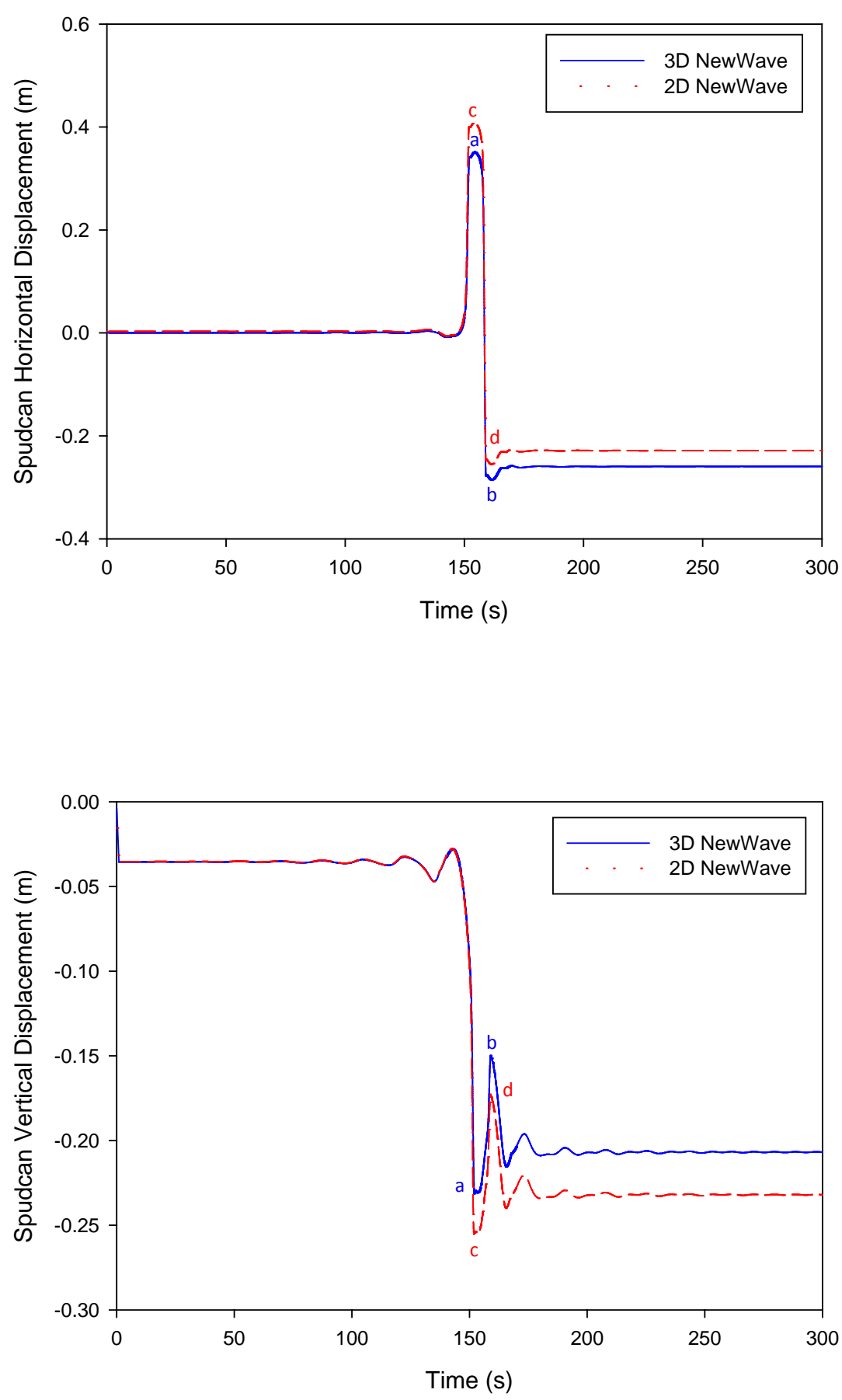

Figure 8. Comparison of the time history of the leeward spudcan displacement for 2D \& 3D NewWaves with 20 m crest height approaching from 08 


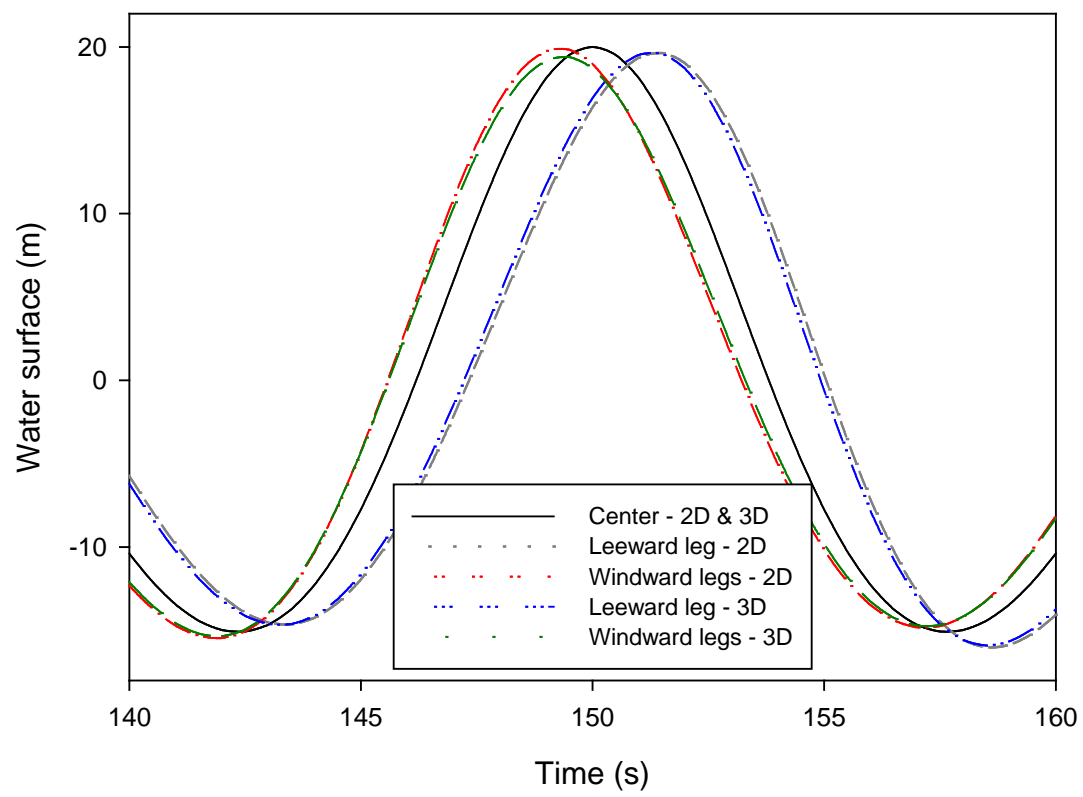

Figure 9. Water surface at the legs $-2 \mathrm{D} \& 3 \mathrm{D}$ NewWaves with $20 \mathrm{~m}$ crest height approaching from $0^{\circ}$ 

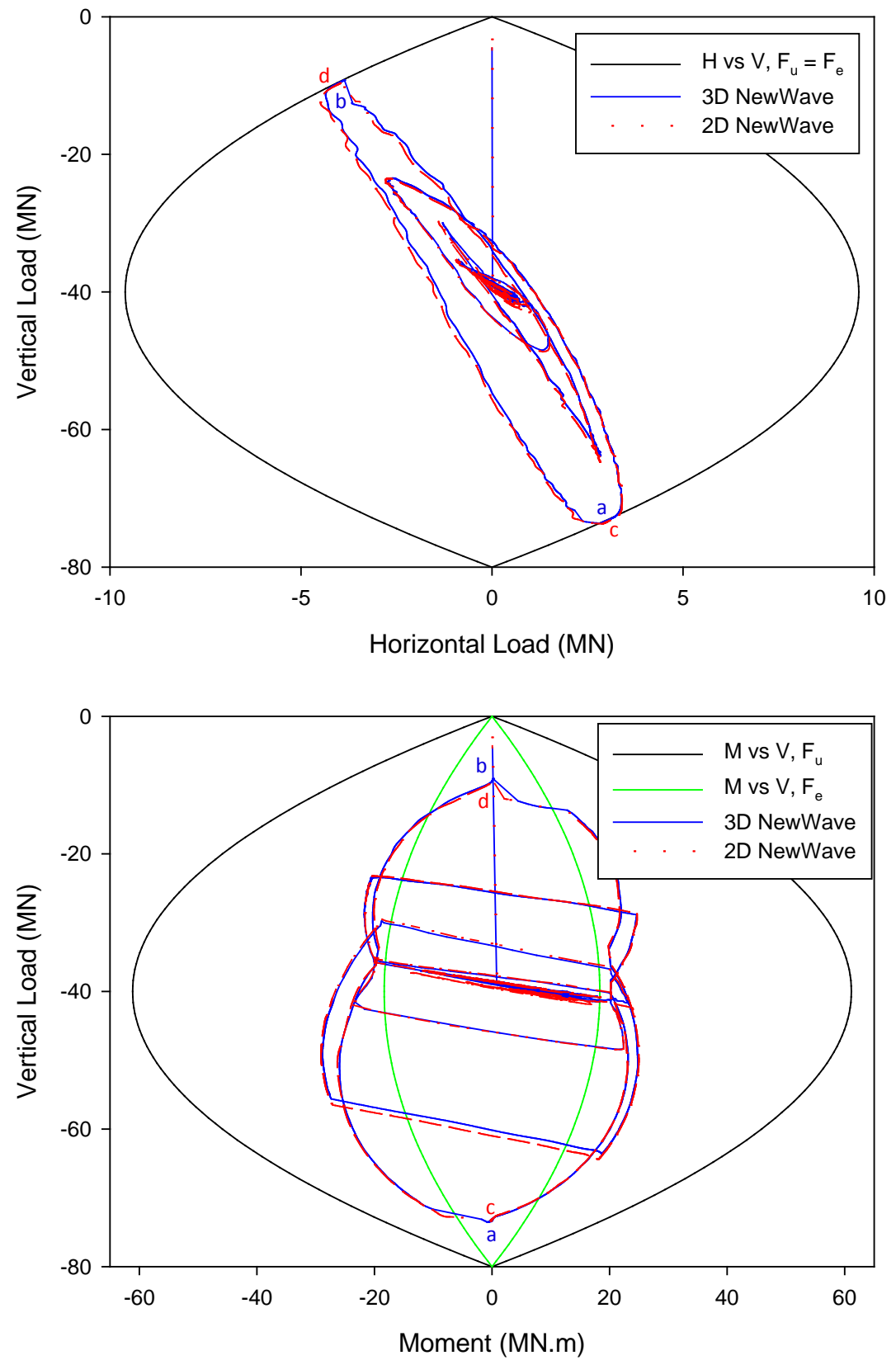

Figure 10. Comparison of the leeward spudcan resultant forces for 2D \& 3D NewWaves with $20 \mathrm{~m}$ crest height 


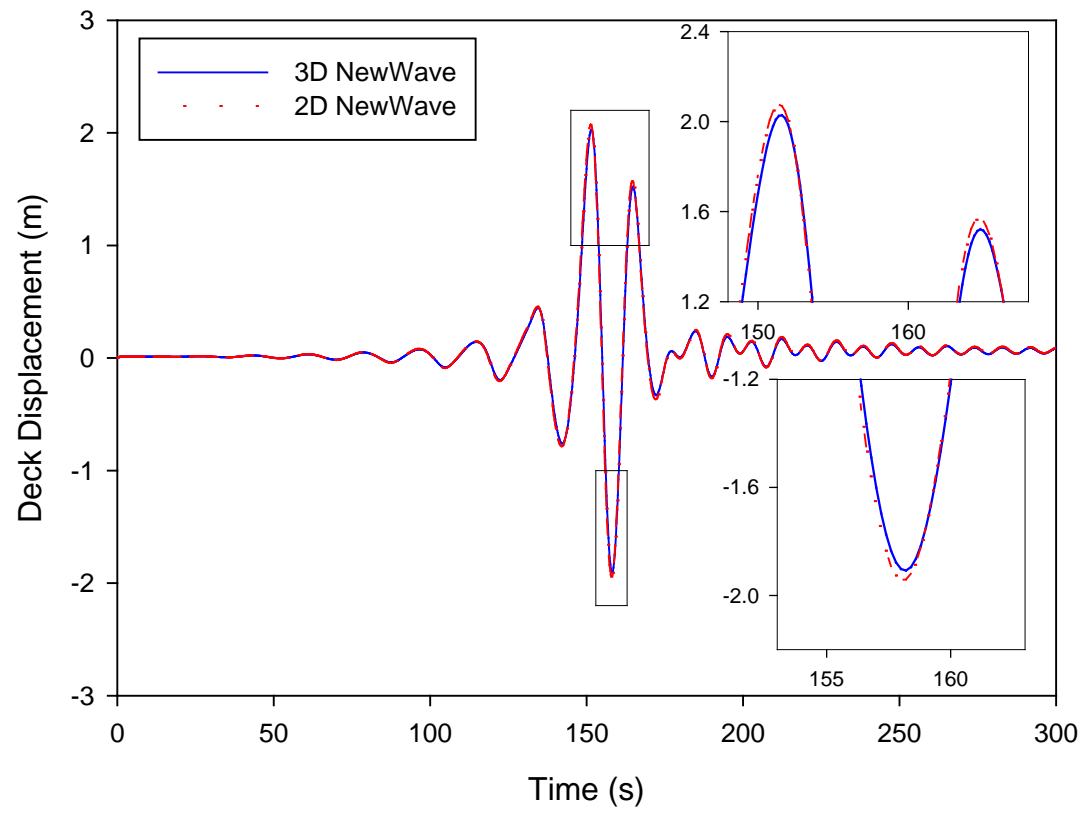

Figure 11. Comparison of the time history of deck displacement for 2D \& 3D NewWaves with $17 \mathrm{~m}$ crest height 


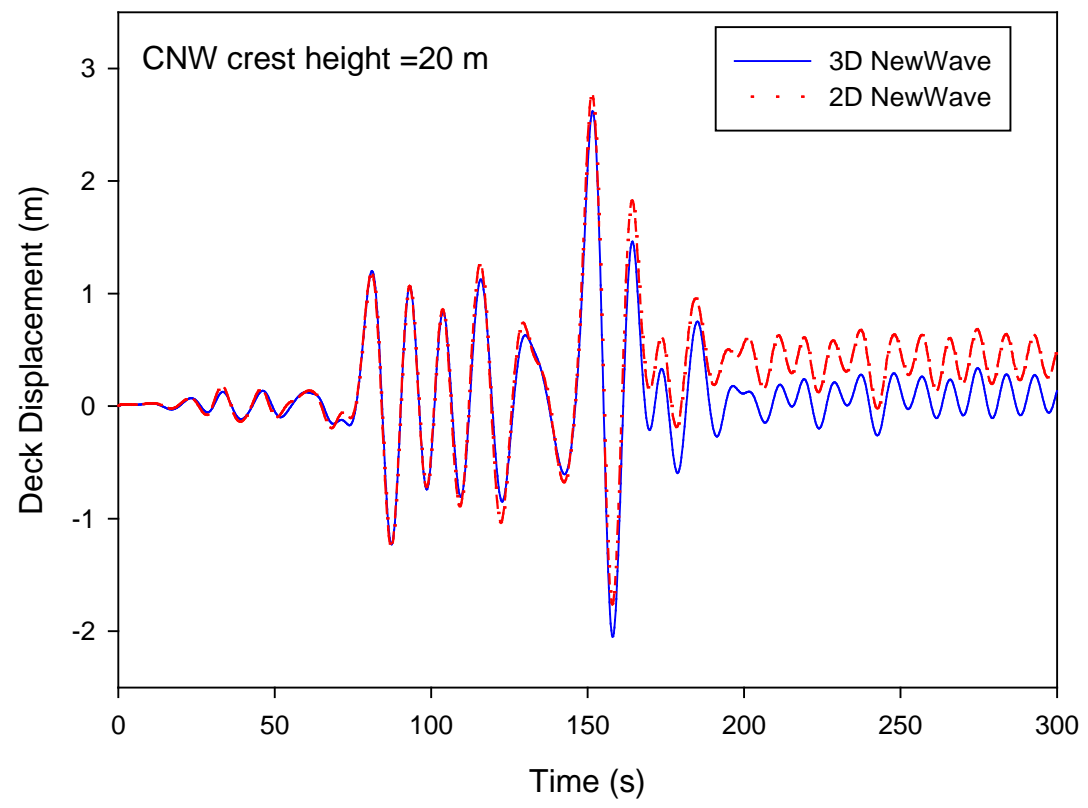

Figure 12. Comparison of the time history of deck displacement for 2D \& 3D CNWs with $20 \mathrm{~m}$ crest height (the deck displacement is in-line with the mean wave direction)

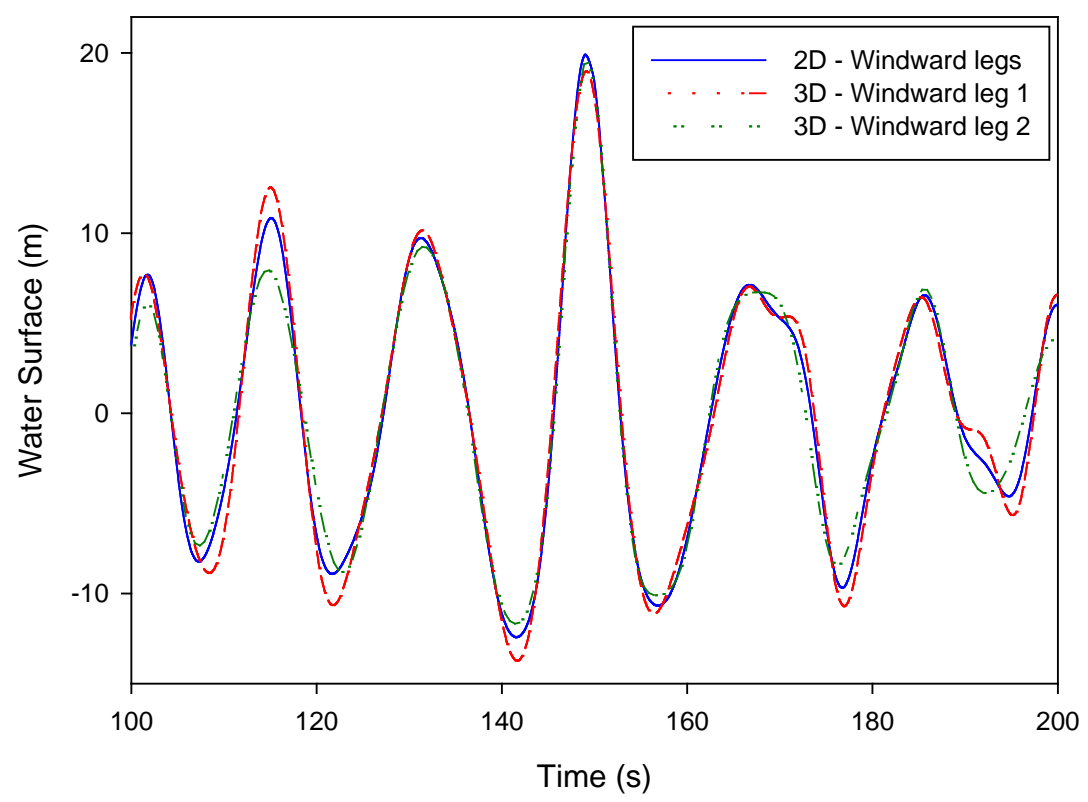

Figure 13. Water surface at the windward legs - 2D \& 3D CNWs with $20 \mathrm{~m}$ crest height 


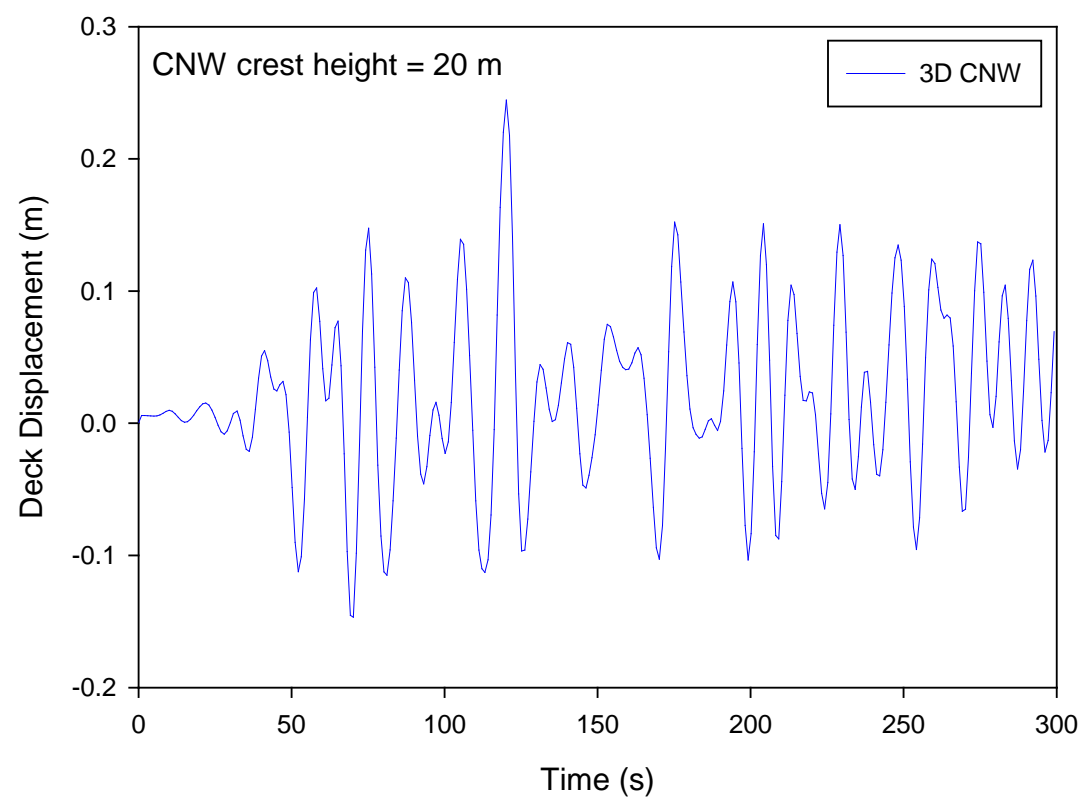

Figure 14. Time history of the deck displacement for 3D CNW with $20 \mathrm{~m}$ crest height (the deck displacement is perpendicular to the mean wave direction) 


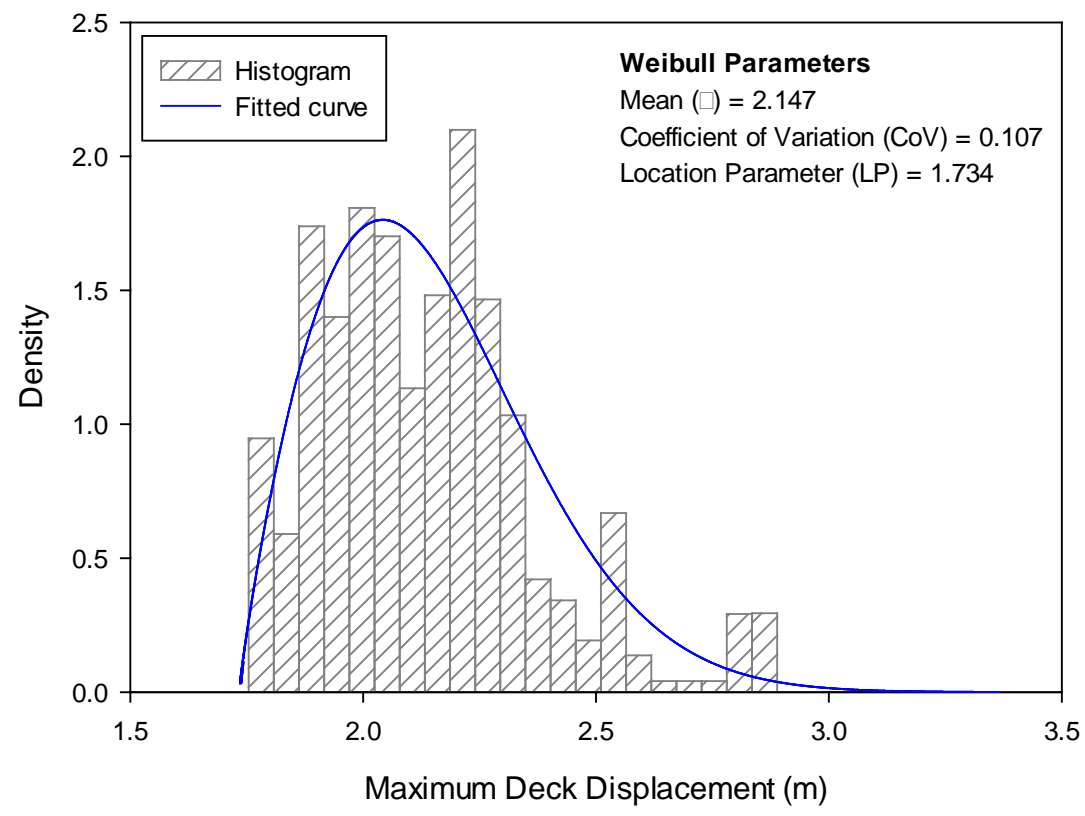

Figure 15. Maximum deck displacement distribution for 100 3D CNWs with $17 \mathrm{~m}$ crest height

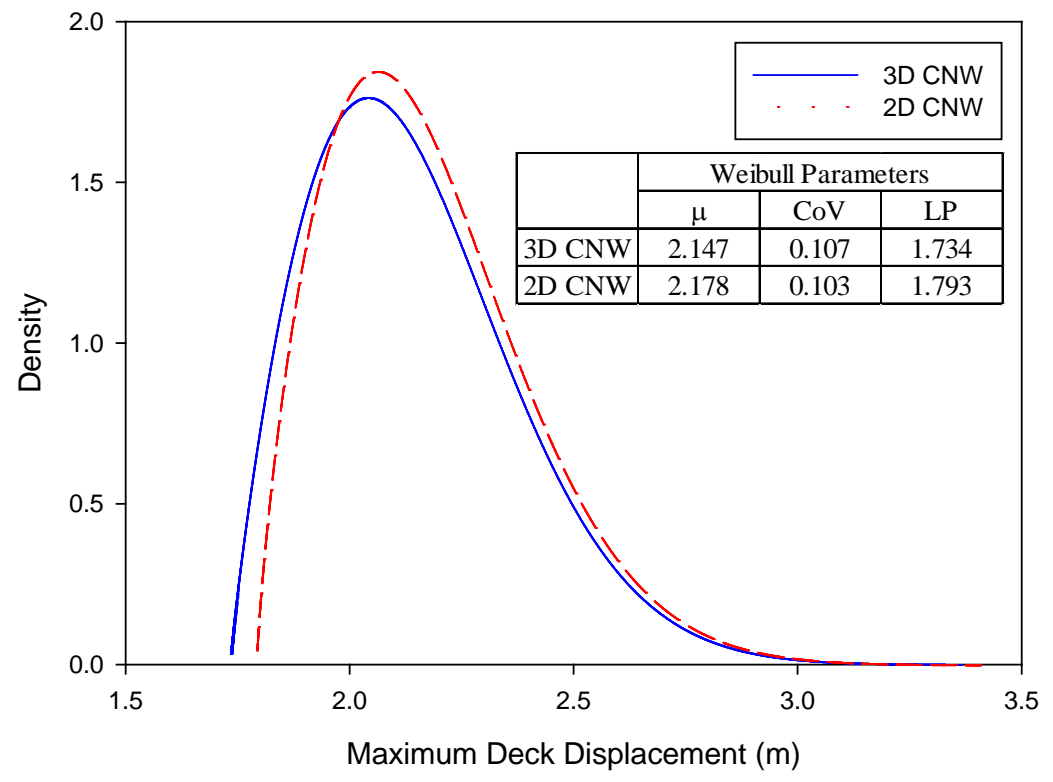

Figure 16. Comparison of the maximum deck displacement distribution for 100 2D \& 3D CNWs with $17 \mathrm{~m}$ crest height 


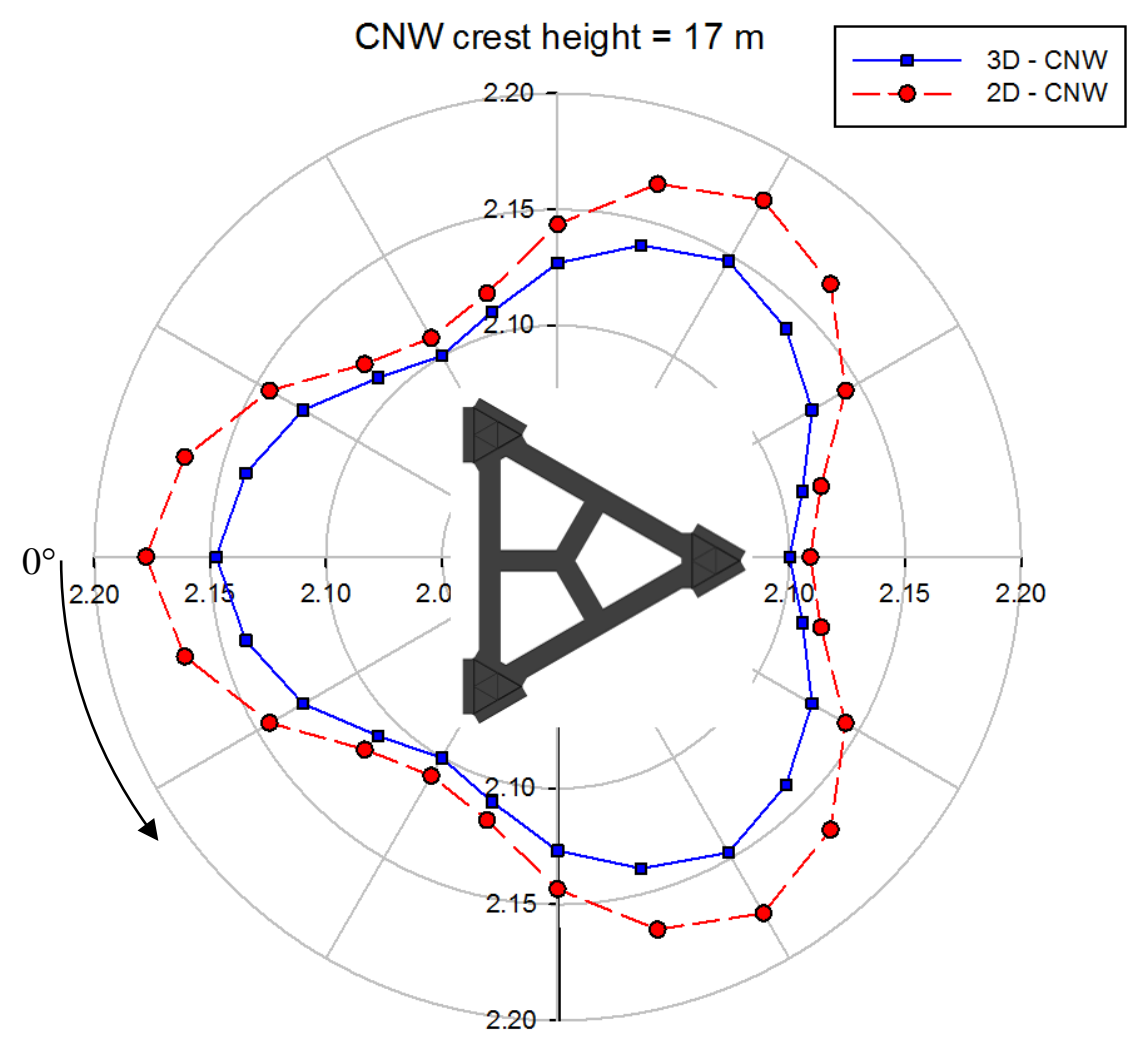

Mean value of maximum deck displacement $(\mathrm{m})$

Figure 17. Comparison of the mean value of the maximum deck displacement distribution for 100 2D \& 3D CNWs that have a $17 \mathrm{~m}$ crest height and approach from different directions 


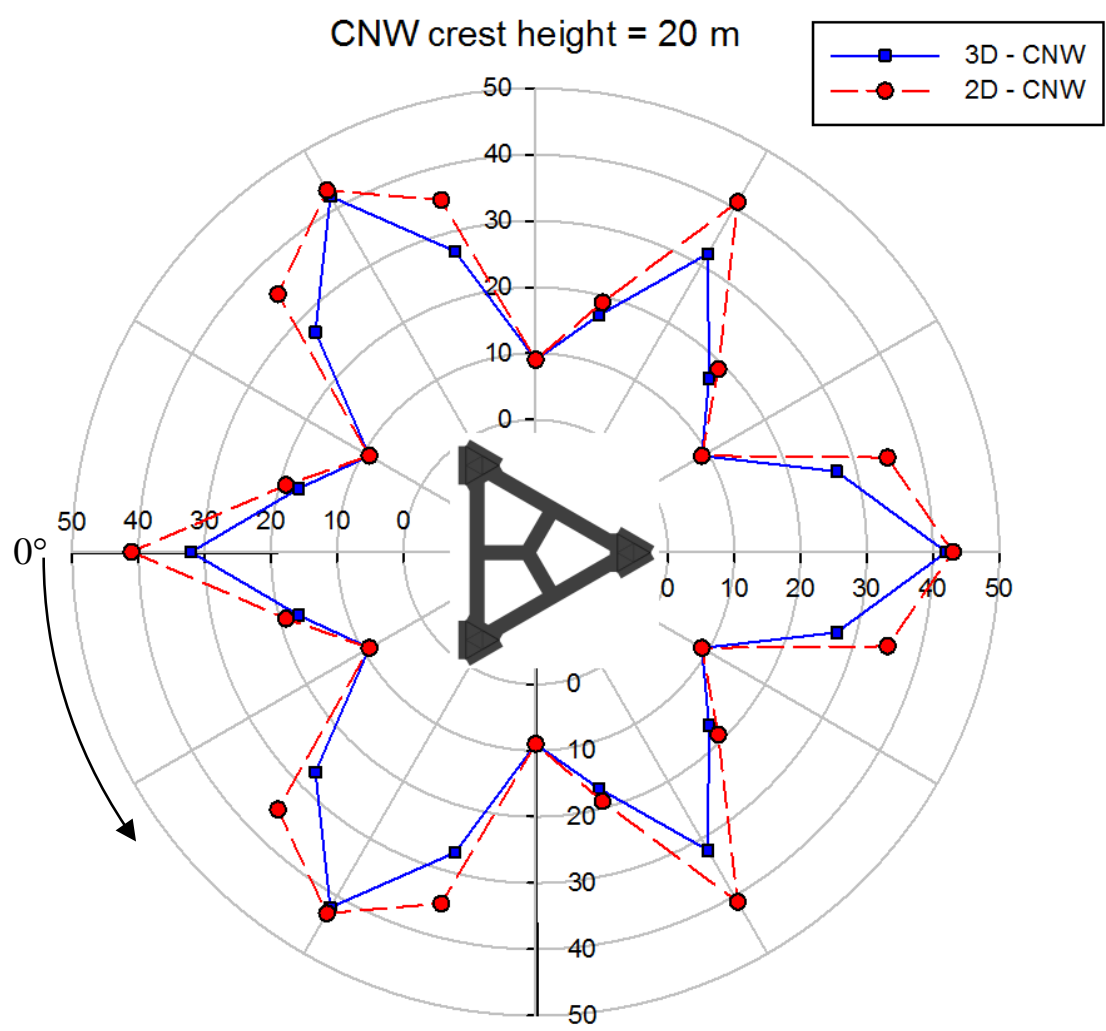

Probability of failure (\%)

Figure 18. Comparison of the probability of failure for 100 2D \& 3D CNWs that have a $20 \mathrm{~m}$ crest height and approach from different directions 

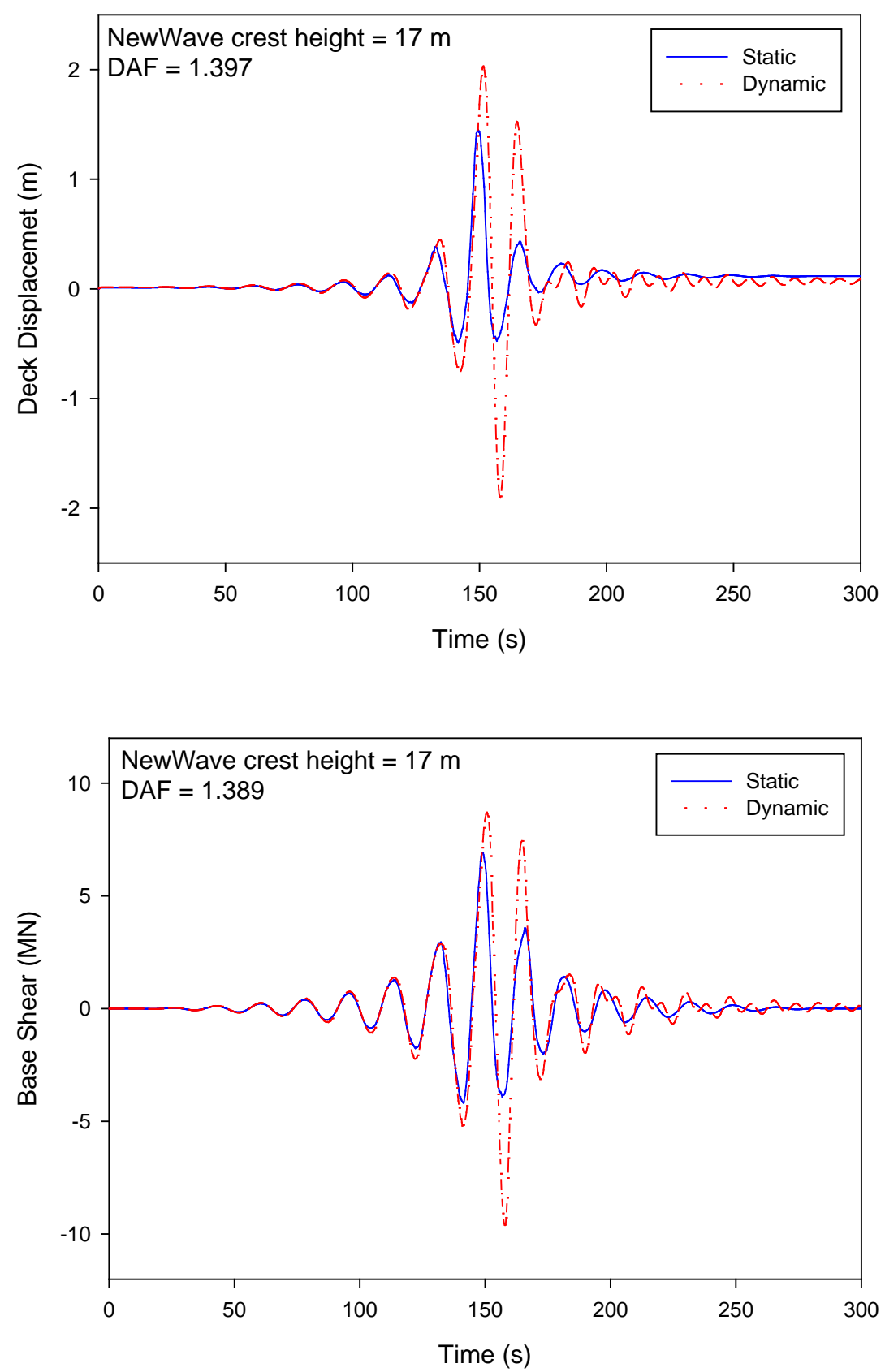

Figure 19. Comparison of the quasi-static and dynamic deck displacements and base shear for 3D NewWave with $17 \mathrm{~m}$ crest height 


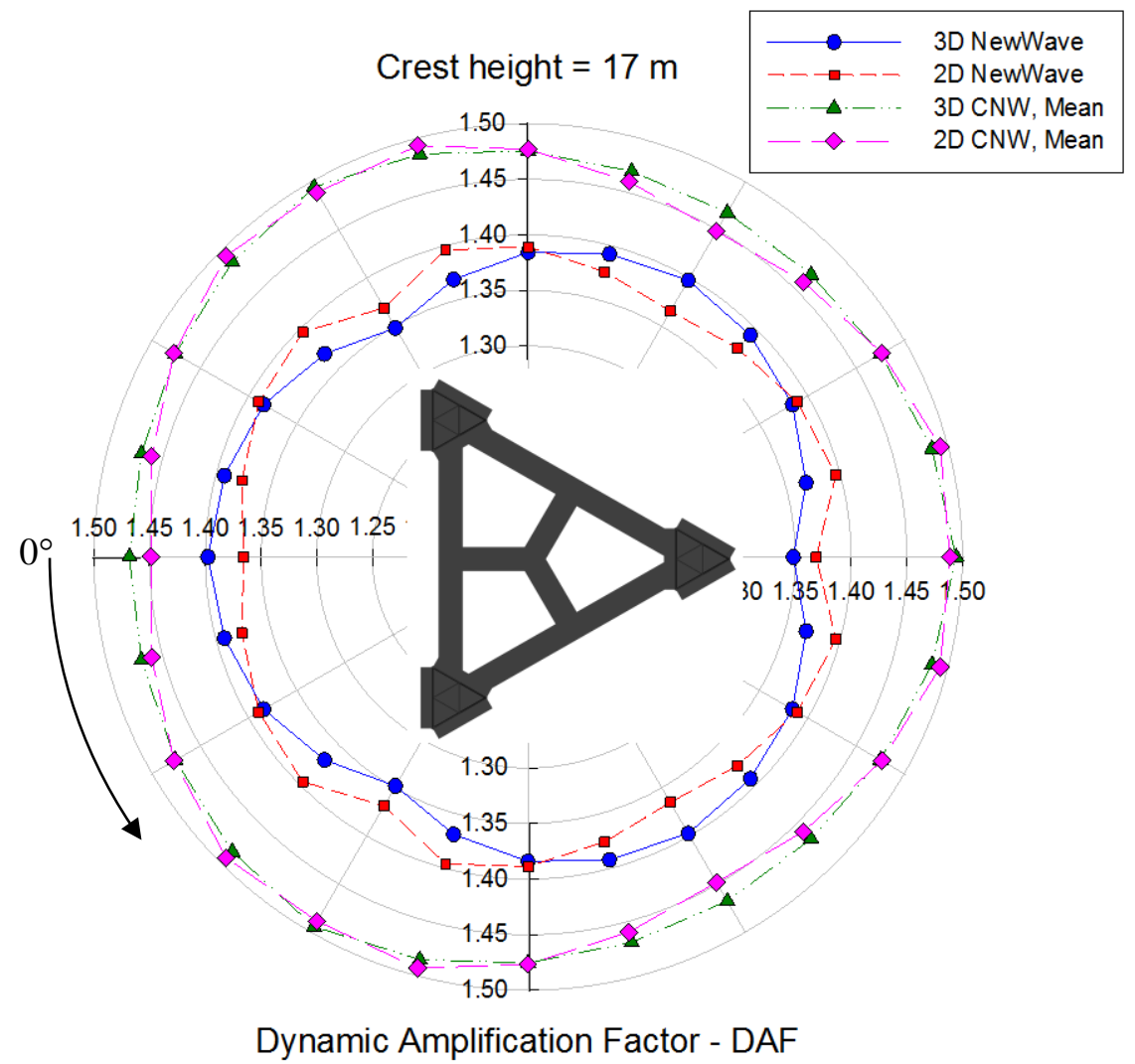

Figure 20. Comparison of the DAF of 2D \& 3D NewWaves with the average of DAF from 100 2D \& 3D CNWs with $17 \mathrm{~m}$ crest height 


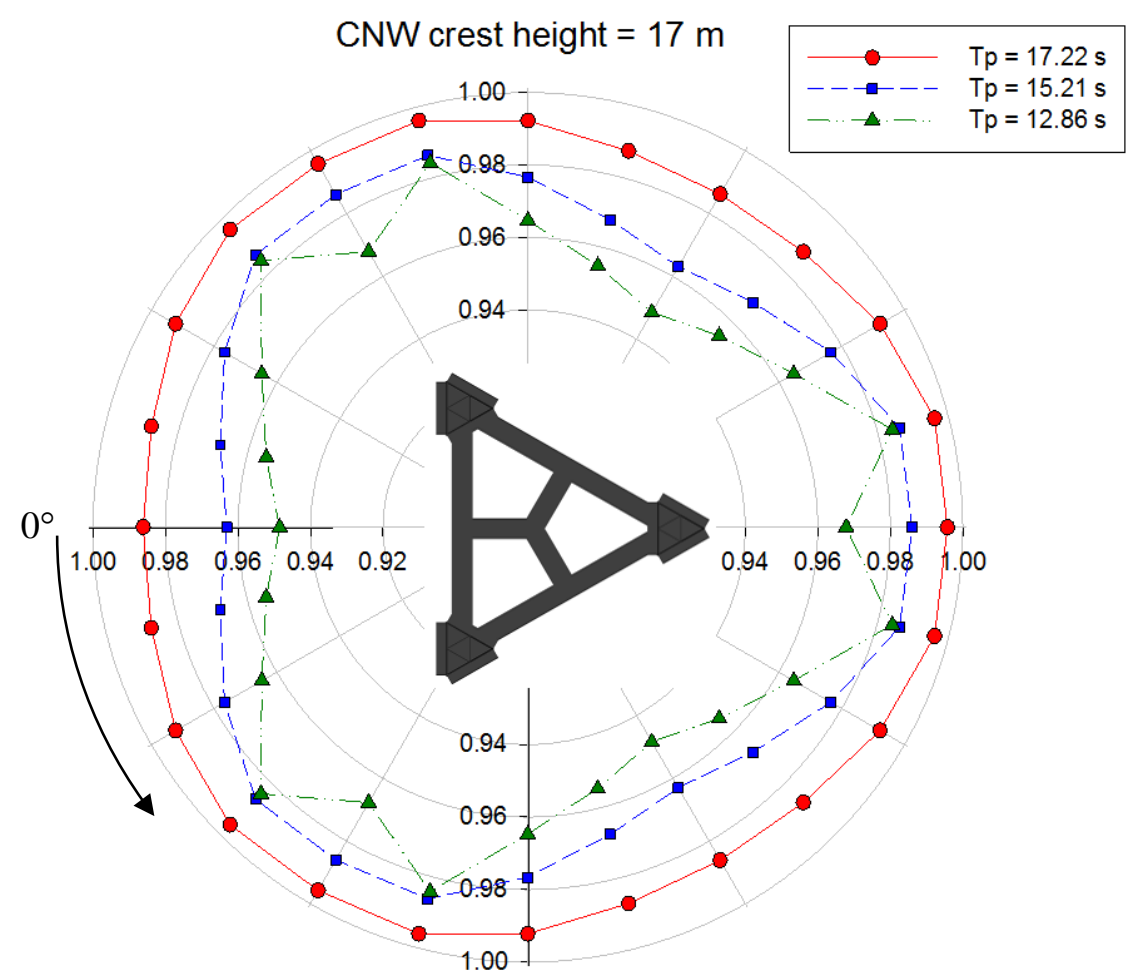

Ratio of 3D to $2 \mathrm{D}$ mean responses

Figure 21. Comparison of the mean values of the Weibull distribution of the maximum deck displacement distribution of 100 2D \& 3D CNWs with $17 \mathrm{~m}$ crest height 


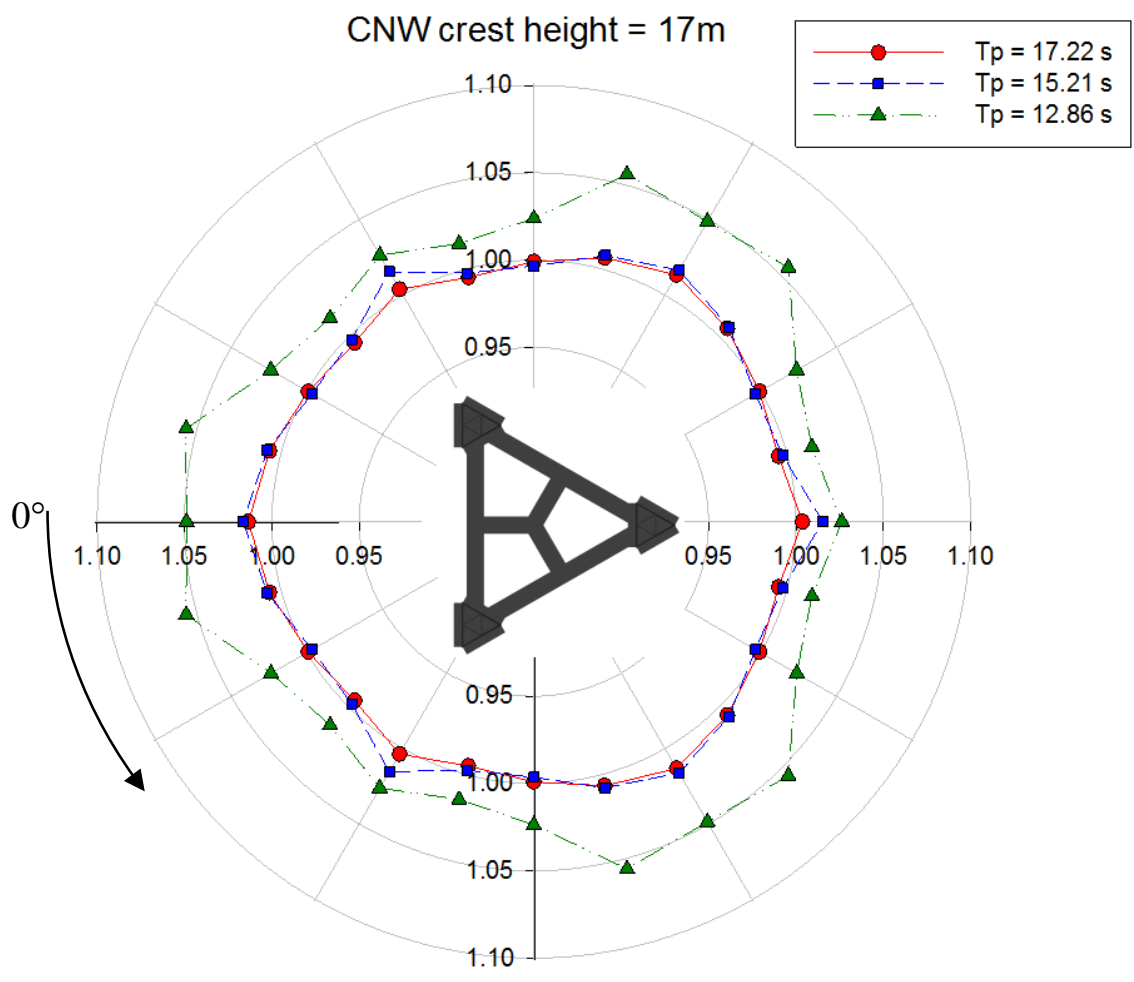

Ratio of the average DAF of $3 \mathrm{D}$ to $2 \mathrm{D}$

Figure 22. Comparison of the DAF of 100 2D \& 3D CNWs with $17 \mathrm{~m}$ crest height 


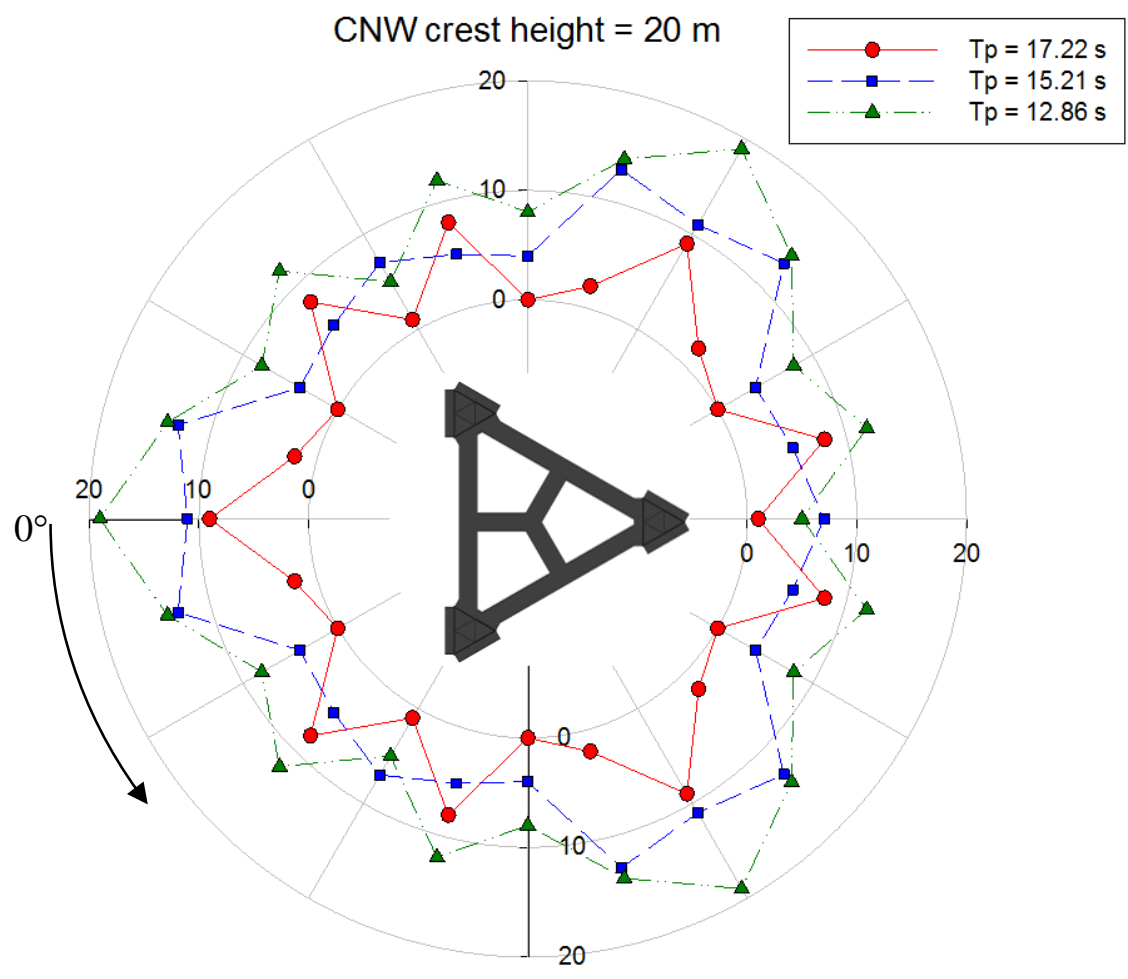

Difference in probability of failure of $2 \mathrm{D} \& 3 \mathrm{D}(2 \mathrm{D}-3 \mathrm{D})(\%)$

Figure 23. Difference in the probability of failure for 100 2D \& 3D CNWs that have a $20 \mathrm{~m}$ crest height and approach from different directions 


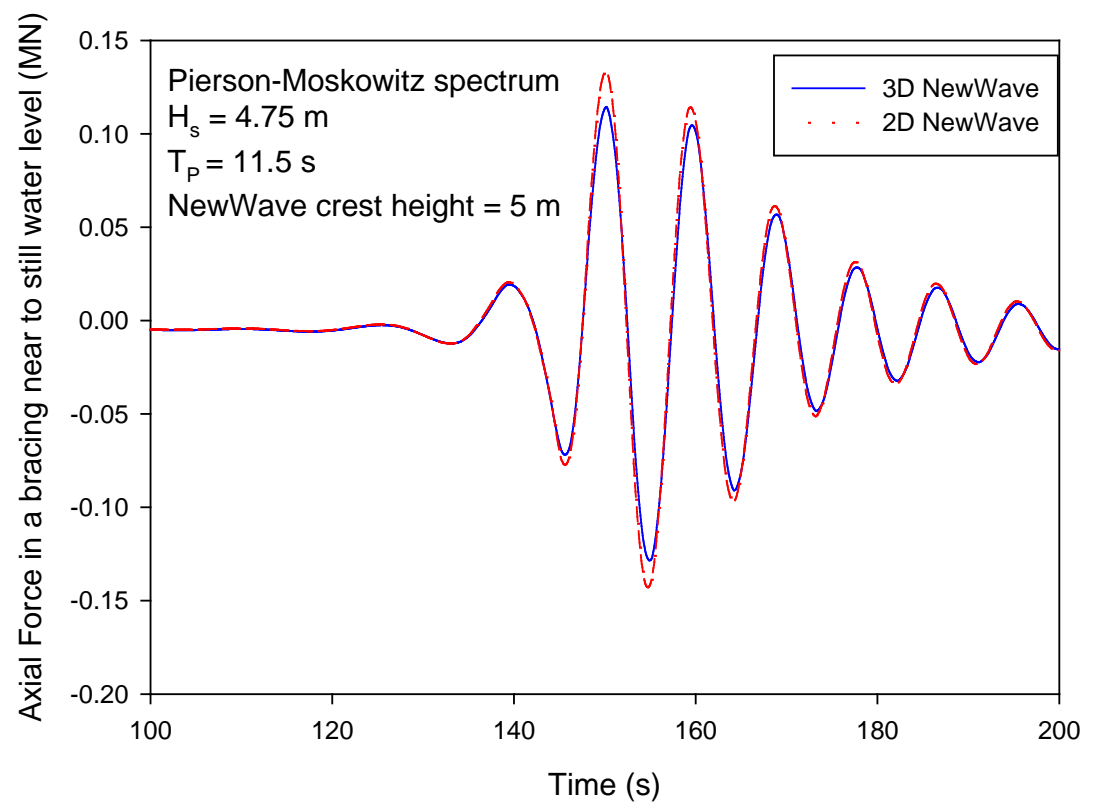

Figure 24. Comparison of the axial force in a bracing near the still-water level for 2D \& 3D NewWave with $5 \mathrm{~m}$ crest height 
Table 1. Comparison of different modes of failure for 100 2D \& 3D CNWs that have a $20 \mathrm{~m}$ crest height and approach from different directions (Preload $=80 \mathrm{MN}$ )

\begin{tabular}{|c|c|c|c|c|c|c|c|c|}
\hline \multicolumn{7}{|c|}{ Modes of failure for different wave directions } \\
\hline $\begin{array}{c}\text { Wave } \\
\text { direction } \\
\left({ }^{\circ}\right)\end{array}$ & $\begin{array}{c}\text { Total number } \\
\text { of failures }\end{array}$ & $\begin{array}{c}\text { Foundation failure } \\
\text { (Punch-through) }\end{array}$ & $\begin{array}{c}\text { Loss of overturning } \\
\text { stability }\end{array}$ & \multicolumn{2}{c|}{ Structural failure } \\
\cline { 2 - 9 } & 2D CNW & 3D CNW & 2D CNW & 3D CNW & 2D CNW & 3D CNW & 2D CNW & 3D CNW \\
\hline 0 & 41 & 32 & 37 & 30 & 4 & 2 & 0 & 0 \\
\hline 15 & 19 & 17 & 18 & 14 & 1 & 3 & 0 & 0 \\
\hline 30 & 9 & 9 & 0 & 1 & 8 & 8 & 1 & 0 \\
\hline 45 & 35 & 27 & 0 & 0 & 35 & 27 & 0 & 0 \\
\hline 60 & 43 & 42 & 0 & 0 & 43 & 42 & 0 & 0 \\
\hline
\end{tabular}

